\title{
Influence of Beam-to-Column Linear Stiffness Ratio on Failure Mechanism of Reinforced Concrete Moment-Resisting Frame Structures
}

\author{
Jizhi Su, Boquan Liu $\mathbb{D}^{D}$, Guohua Xing $\mathbb{D}^{D}$, Yudong Ma, and Jiao Huang \\ School of Civil Engineering, Chang'an University, Xi'an 710061, China \\ Correspondence should be addressed to Guohua Xing; ghxing@chd.edu.cn
}

Received 22 July 2019; Revised 30 October 2019; Accepted 11 December 2019; Published 10 January 2020

Academic Editor: Roberto Nascimbene

Copyright ( 2020 Jizhi Su et al. This is an open access article distributed under the Creative Commons Attribution License, which permits unrestricted use, distribution, and reproduction in any medium, provided the original work is properly cited.

\begin{abstract}
The design philosophy of a strong-column weak-beam (SCWB), commonly used in seismic design codes for reinforced concrete (RC) moment-resisting frame structures, permits plastic deformation in beams while keeping columns elastic. SCWB frames are designed according to beam-to-column flexural capacity ratio requirements in order to ensure the beam-hinge mechanism during large earthquakes and without considering the influence of the beam-to-column stiffness ratio on the failure modes of global structures. The beam-to-column linear stiffness ratio is a comprehensive indicator of flexural stiffness, story height, and span. This study proposes limit values for different aseismic grades based on a governing equation deduced from the perspective of member ductility. The mathematical expression shows that the structural yielding mechanism strongly depends on parameters such as material strength, section size, reinforcement ratio, and axial compression ratio. The beam-hinge mechanism can be achieved if the actual beam-to-column linear stiffness ratio is smaller than the recommended limit values. Two 1/3-scale models of 3-bay, 3story RC frames were constructed and tested under low reversed cyclic loading to verify the theoretical analysis and investigate the influence of the beam-to-column linear stiffness ratio on the structural failure patterns. A series of nonlinear dynamic analyses were conducted on the numerical models, both nonconforming and conforming to the beam-to-column linear stiffness ratio limit values. The test results indicated that seismic damage tends to occur at the columns in structures with larger beam-to-column linear stiffness ratios, which inhibits the energy dissipation. The dynamic analysis suggests that considering the beam-to-column linear stiffness ratio during the design of structures leads to a transition from a column-hinge mechanism to a beamhinge mechanism.
\end{abstract}

\section{Introduction}

Reinforced concrete (RC) frames are the most widely used structural systems for multistory industrial and civil buildings around the world. However, in recent decades, many buildings have exhibited poor seismic behavior during strong earthquakes due to the failure of the weaker vertical members, while the horizontal elements remained mostly elastic [1]. The proper internal force distribution of beams and columns is an important design principle that has significant effects on the failure mechanism of RC frame structures.

The design philosophy of strong-column weak-beam (SCWB) is applied to ensure that the sum of the ultimate flexural capacity of all columns should be larger than that of the beams at the beam-to-column joints locally. This requirement can be expressed as $\Sigma M_{\mathrm{uc}} / \Sigma M_{\mathrm{ub}}>\eta_{\mathrm{amp}}$, where $M_{\mathrm{uc}}$ and $M_{\mathrm{ub}}$ represent the ultimate flexural capacity of the columns and beams, respectively, and $\eta_{\mathrm{amp}}$ represents the amplification factor, which varies from code to code. Code ACI318-14 [2] specifies the factor as 1.2, while Eurocode 8 [3] proposes a SCWB ratio of 1.3; Chinese Code [4] defines different values according to aseismic grade, which is classified based on fortification intensity, structural form, and building height to meet different ductility requirements. The values are 1.7 for Grade 1, 1.5 for Grade 2, 1.3 for Grade 3, and 1.2 for Grade 4; TEC-2007 [5] requires that the sum of the ultimate moment capacity of columns should be at least 
$20 \%$ larger than that of beams at the same joint; NZS3101 [6] defines a dynamic amplification coefficient for the upper story of structure to consider the higher mode, which varies with the natural period and structural height. However, numerous studies have shown that these seismic design code provisions may not be adequate to prevent the column-hinge mechanism; that is, the demand values of the SCWB ratio are usually larger than the code specifications. Nakashima and Sawaizumi [7] studied the column-to-beam strength ratio for ensuring the elastic response of columns based on a steel moment frame model. They found that the strength ratio increased with the amplitude of ground motion and reached a value of 1.5 when the amplitude was $0.5 \mathrm{~m} / \mathrm{s}$. Dooley and Bracci [8] compared the seismic response of 3- and 6-story RC frame structures with different SCWB ratios varying from 0.8 to 2.4 and found that a minimum strength ratio of 2.0 was effective to prevent the column-hinge mechanism. Kuntz and Browning [9] analyzed the seismic performance of 4- and 16-story RC frame structures. They found that the strength ratio for inducing the beam-hinge mechanism increased with the structural height and defined a locationdependent SCWB ratio. Medina and Krawinkler [10] investigated the influence of parameters such as the natural period, story number, and seismic level on the strength ratio for ensuring the beam-hinge mechanism and determined that the required flexural strength of columns was proportional to the natural period and seismic level. Ibarra and Krawinkler [11] studied the seismic behavior of 9- and 18story RC frame buildings and suggested that a SCWB ratio of 3.0 was needed to prevent the column-hinge mechanism. Haselton et al. [12] studied the collapse probability of RC frame buildings with different SCWB ratios. Their results showed that a SCWB ratio of 1.2 was required for a 4 -story frame and 3.0 for a 12-story frame, and a height-dependent SCWB ratio was proposed.

The major limitation of these previous studies in the research field of RC structural seismic performance is that they primarily focus on the relative flexural strength of beams and columns. The subject that has been largely ignored is how the relative stiffness of beams and columns affects the failure patterns of RC building structures. Consequently, there are no specific provisions for the beam-to-column linear stiffness ratio in the seismic design of RC frame buildings. The beam-to-column linear stiffness ratio could reflect the variation of flexural stiffness, story height, and span comprehensively and have significant effects on the seismic behavior of RC frame structures. The main objective of this study is to investigate the influence of the beam-to-column linear stiffness ratio on the failure modes of RC frame structures. A governing equation for controlling the structural yielding mechanism is deduced considering member ductility, and various limit values of beam-to-column linear stiffness ratio are suggested for different aseismic grades. Subsequently, pseudostatic tests of RC frames are discussed with the purpose of verifying the theoretical analysis and investigating the influence of the beam-to-column linear stiffness ratio on the structural seismic performance. Furthermore, a series of nonlinear dynamic analyses are conducted on RC plane frames with different seismic fortification intensities. These prototype buildings are designed both nonconforming and conforming to the proposed limit values. Plastic hinge distribution and component plastic deformation are compared to highlight the significance of the beam-to-column linear stiffness ratio.

\section{Limit Values of Beam-to-Column Linear Stiffness Ratio}

2.1. Strong-Column Weak-Beam Criterion. RC frame structures usually exhibit two types of yielding mechanisms during strong earthquakes: strong-column weak-beam and strong-beam weak-column. In the SCWB yielding mechanism, the plastic hinges of structures are induced to concentrate at the ends of beams and the bottoms of first-story columns. Plastic hinges of columns should be delayed or even avoided, and most of the seismic energy should be dissipated by the plastic hinges of beams. In comparison, the strong-beam weak-column yielding mechanism usually results in the failure of an individual story or structural collapse, due to the weak layer caused by the concentration of plastic hinges in the columns.

The columns which act as the major vertical members and lateral force-resisting members have an important effect on the overall stability of structures [13]. The beams are also involved in lateral force resistance and structural stability, but structural damage caused by beam failure is less serious than that caused by column failure. On this basis, SCWB is the preferred yielding mechanism because the deformation capacity of the overall structure could be fully utilized, by mobilizing its ductility. The SCWB yielding mechanism can be expressed in terms of member ductility in that the beam sections reach the yield point in advance of the column sections. The following relationships should be satisfied to achieve this yielding mechanism:

$$
\left\{\begin{array}{l}
\chi_{\mathrm{b}}=\frac{\theta_{\mathrm{yb}}}{\theta_{\mathrm{b}}} \leq 1, \\
\chi_{\mathrm{c}}=\frac{\theta_{\mathrm{yc}}}{\theta_{\mathrm{c}}}>1,
\end{array}\right.
$$

where $\chi_{\mathrm{b}}$ and $\chi_{\mathrm{c}}$ are the parameters to characterize the rotation capacity of the beams and columns, respectively; $\theta_{\mathrm{yb}}$ and $\theta_{\mathrm{yc}}$ are the yield rotation angles of the beam and column sections, respectively; and $\theta_{\mathrm{b}}$ and $\theta_{\mathrm{c}}$ are the measured rotation angles of the beam and column sections during an earthquake, respectively.

2.2. Governing Equation of Strong-Column Weak-Beam. Considering the mechanical model of the beam-to-column substructures of regular RC plane frame structures, the governing equation for the beam-to-column linear stiffness ratio that facilitates the SCWB mechanism is deduced. The calculation model is shown in Figure 1.

The following assumptions are made: (a) the bond-slip between steel and concrete is not considered, nor is the 


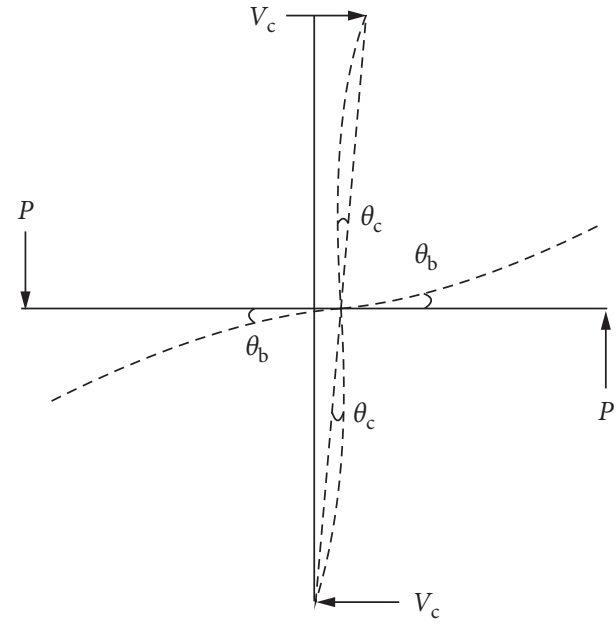

FIgURE 1: Mechanical model of beam-column substructures.

tension of the concrete material or shear deformation of members; (b) the deformed sections of members remain plane; and (c) strain is linearly distributed along the section height. The compressive stress-strain curves of concrete and steel are represented as follows:

The stress-strain curves of concrete are represented as

$$
\sigma_{\mathrm{c}}= \begin{cases}f_{\mathrm{c}}\left[1-\left(1-\frac{\varepsilon_{\mathrm{c}}}{\varepsilon_{0}}\right)^{n}\right], & \varepsilon_{\mathrm{c}} \leq \varepsilon_{0}, \\ f_{\mathrm{c}}, & \varepsilon_{0}<\varepsilon_{\mathrm{c}} \leq \varepsilon_{\mathrm{cu}},\end{cases}
$$

where $f_{\mathrm{c}}$ is the axial compressive strength of concrete; $\varepsilon_{0}$ is the compressive strain corresponding to $f_{c}, \varepsilon_{0}=0.002+$ $0.5 \times\left(f_{\mathrm{cu}, k-50}\right) \times 10^{-5}$, taken as 0.002 for $\varepsilon_{0}<0.002 ; \varepsilon_{\mathrm{cu}}$ is the ultimate compressive strain of concrete, $\varepsilon_{\mathrm{cu}}=0.0033-0.5 \times$ $\left(f_{\mathrm{cu}, k-50}\right) \times 10^{-5}$, taken as 0.0033 for $\varepsilon_{\mathrm{cu}}>0.0033$; and $n$ is a coefficient, $n=2-1 / 60 \times\left(f_{\text {cu } k-50}\right)$, taken as 2.0 for $n>2.0$.

The stress-strain curves of steel are represented as

$$
\sigma_{\mathrm{s}}=\left\{\begin{array}{cc}
E_{\mathrm{s}} \varepsilon_{\mathrm{s}}, & \varepsilon_{\mathrm{s}} \leq \varepsilon_{\mathrm{sy}}, \\
f_{\mathrm{y}}, & \varepsilon_{\mathrm{s}}>\varepsilon_{\mathrm{sy}},
\end{array}\right.
$$

where $f_{\mathrm{y}}$ is the yield strength of steel, $\varepsilon_{\text {sy }}$ is the yield strain corresponding to $f_{\mathrm{y}}$, and $E_{\mathrm{s}}$ is the elastic modulus.

2.2.1. Yield Deformation of Beams. The yield curvature of a beam section $\varphi_{\mathrm{yb}}$ is determined for the following conditions: the strain of the tensile reinforcements reaches the yield point $\left(\varepsilon_{\mathrm{s}}=\varepsilon_{\mathrm{sy}}\right)$, the strain of concrete at the edge of the compression zone is less than the peak strain $\left(\varepsilon_{\mathrm{c}}<\varepsilon_{0}\right)$, and the strain of the reinforcements in the compression zone is relatively small $\left(\varepsilon_{\mathrm{s}}^{\prime}<\varepsilon_{\text {sy }}\right)$.

The force diagram is shown in Figure 2, where $x$ is the distance from one point in the compression zone to the neutral axis and $\varepsilon$ is the concrete strain corresponding to the point, obtained from the geometric similarity relation on the basis of the plane-section assumption:

$$
\begin{gathered}
\varepsilon=\frac{\varepsilon_{\mathrm{sy}}}{h_{0}-x_{\mathrm{c}}} x, \\
\varepsilon_{\mathrm{s}}^{\prime}=\frac{x_{\mathrm{c}}-a_{\mathrm{s}}^{\prime}}{h_{0}-x_{\mathrm{c}}} \varepsilon_{\mathrm{sy}}
\end{gathered}
$$

where $h_{0}$ is the distance from the resultant point of tensile reinforcements to the edge of the compression zone and $x_{\mathrm{c}}$ is the height of the compression zone, corresponding to the section yielding.

The concrete stress in the compression zone is expressed as follows:

$$
\sigma_{\mathrm{c}}=f_{\mathrm{c}}\left[1-\left(1-\frac{\varepsilon}{\varepsilon_{0}}\right)^{n}\right]
$$

By substituting equation (4) into equation (6), we get

$$
\sigma_{\mathrm{c}}(x)=f_{\mathrm{c}}\left[1-\left(1-\frac{\varepsilon_{\mathrm{sy}}}{\varepsilon_{0}} \cdot \frac{x}{h_{0}-x_{\mathrm{c}}}\right)^{n}\right] \text {. }
$$

The resultant force of concrete in the compression zone is expressed as follows:

$$
\begin{aligned}
C & =\int_{0}^{x_{\mathrm{c}}} \sigma_{\mathrm{c}}(x) b \cdot \mathrm{d} x \\
& =f_{\mathrm{c}} b\left\{x_{\mathrm{c}}+\left(h_{0}-x_{\mathrm{c}}\right) \frac{\varepsilon_{0}}{(1+n) \varepsilon_{\mathrm{sy}}}\left[\left(1-\frac{x_{\mathrm{c}}}{h_{0}-x_{\mathrm{c}}} \cdot \frac{\varepsilon_{\mathrm{sy}}}{\varepsilon_{0}}\right)^{n+1}-1\right]\right\} .
\end{aligned}
$$

From the equilibrium of axial force shown in Figure 2, the following can be obtained:

$$
C+A_{\mathrm{s}}^{\prime} E_{\mathrm{s}}^{\prime} \varepsilon_{\mathrm{s}}^{\prime}=A_{\mathrm{s}} f_{\mathrm{y}} .
$$

By substituting equations (5) and (8) into equation (9), we get

$$
A_{\mathrm{s}} f_{\mathrm{y}}=A_{\mathrm{s}}^{\prime} E_{\mathrm{s}} \frac{x_{\mathrm{c}}-a_{\mathrm{s}}^{\prime}}{h_{0}-x_{\mathrm{c}}} \varepsilon_{\mathrm{sy}}+f_{\mathrm{c}} b\left\{x_{\mathrm{c}}+\left(h_{0}-x_{\mathrm{c}}\right) \frac{\varepsilon_{0}}{(1+n) \varepsilon_{\mathrm{sy}}}\left[\left(1-\frac{x_{\mathrm{c}}}{h_{0}-x_{\mathrm{c}}} \cdot \frac{\varepsilon_{\mathrm{sy}}}{\varepsilon_{0}}\right)^{n+1}-1\right]\right\} .
$$

Dividing both sides of equation (10) by $f_{c} b h_{0}$ and defining $\xi_{\mathrm{yb}}=x_{\mathrm{c}} / h_{0}, \rho=A_{\mathrm{s}} / b h_{0}$ (the reinforcement ratio of tensile steel), and $\rho^{\prime}=A_{\mathrm{s}}^{\prime} / b h_{0}$ (the reinforcement ratio of compressive steel), equation (11) can be obtained, where $\xi_{\mathrm{yb}}$ is obtained by equation (11), and the yield curvature of the beam section is then calculated according to the geometric relationship: 


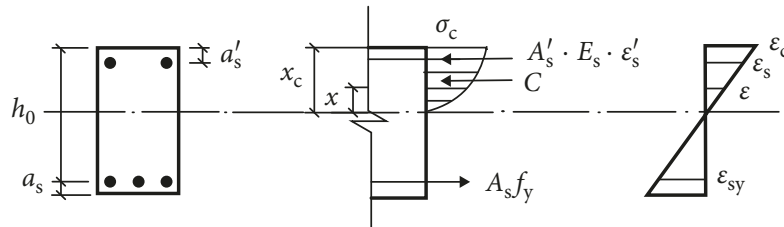

FIGURE 2: Force diagram of the beam section.

$$
\begin{aligned}
\rho \frac{f_{\mathrm{y}}}{f_{\mathrm{c}}}= & \rho^{\prime} \cdot \frac{f_{\mathrm{y}}\left(\xi_{\mathrm{yb}}-a_{\mathrm{s}}^{\prime} / h_{0}\right)}{f_{\mathrm{c}}\left(1-\xi_{\mathrm{yb}}\right)}+\xi_{\mathrm{yb}}+\left(1-\xi_{\mathrm{yb}}\right) \frac{\varepsilon_{0}}{\varepsilon_{\mathrm{sy}}} \frac{1}{n+1} \\
& \cdot\left[\left(1-\frac{\xi_{\mathrm{yb}}}{1-\xi_{\mathrm{yb}}} \cdot \frac{\varepsilon_{\mathrm{sy}}}{\varepsilon_{0}}\right)^{n+1}-1\right] .
\end{aligned}
$$

2.2.2. Yield Deformation of Columns. The yield curvature of column section $\varphi_{\mathrm{yc}}$ is determined for the following conditions: the strain at which the concrete at the edge of the compression zone reaches the peak strain $\left(\varepsilon_{\mathrm{c}}=\varepsilon_{0}\right)$, the strain at which the reinforcements in the compression zone are less than the yield point $\left(\varepsilon_{\mathrm{s}}^{\prime}<\varepsilon_{\mathrm{sy}}\right)$, and the strain of the tensile reinforcements reaches the yield point $\left(\varepsilon_{\mathrm{s}}=\varepsilon_{\mathrm{sy}}\right)$. The force diagram is shown in Figure 3. According to the plane-section assumption, the following equations can be obtained from the geometric similarity relation:

$$
\begin{array}{r}
\frac{\varepsilon}{x}=\frac{\varepsilon_{0}}{x_{\mathrm{c}}}, \\
\frac{\varepsilon_{\mathrm{s}}^{\prime}}{x_{\mathrm{c}}-a_{\mathrm{s}}^{\prime}}=\frac{\varepsilon_{0}}{x_{\mathrm{c}}}, \\
\frac{\varepsilon_{\mathrm{sy}}}{h_{0}-x_{\mathrm{c}}}=\frac{\varepsilon_{0}}{x_{\mathrm{c}}} .
\end{array}
$$

The concrete stress in the compression zone is expressed as follows:

$$
\sigma_{\mathrm{c}}(x)=f_{\mathrm{c}}\left[1-\left(1-\frac{x}{x_{\mathrm{c}}}\right)^{n}\right] .
$$

The resultant force of concrete in the compression zone is expressed as follows:

$$
C=\int_{0}^{x_{\mathrm{c}}} \sigma_{\mathrm{c}}(x) b \cdot \mathrm{d} x=\frac{n}{n+1} \cdot f_{\mathrm{c}} b x_{\mathrm{c}} .
$$

From the equilibrium of axial force shown in Figure 3, the following equation is obtained:

$$
C+A_{\mathrm{s}}^{\prime} E_{\mathrm{s}}^{\prime} \varepsilon_{\mathrm{s}}^{\prime}=N+A_{\mathrm{s}} E_{\mathrm{s}} \varepsilon_{\mathrm{sy}} .
$$

By substituting equations (13), (14), and (16) into (17), we get

$$
\frac{n}{n+1} f_{\mathrm{c}} b x_{\mathrm{c}}+A_{\mathrm{s}}^{\prime}\left(x_{\mathrm{c}}-a_{\mathrm{s}}^{\prime}\right) \frac{\varepsilon_{0}}{x_{\mathrm{c}}}=N+E_{\mathrm{s}} A_{\mathrm{s}}\left(h_{0}-x_{\mathrm{c}}\right) \frac{\varepsilon_{0}}{x_{\mathrm{c}}} .
$$

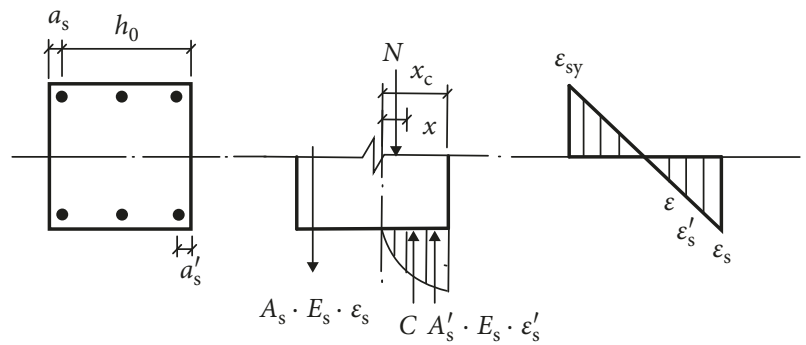

Figure 3: Force diagram of the column section.

Dividing both sides of equation (18) by $f_{\mathrm{c}} b h_{0}$ and defining $\xi_{\mathrm{yb}}=x_{\mathrm{c}} / h_{0}, \rho=A_{\mathrm{s}} / b h_{0}$, and $\rho^{\prime}=A_{\mathrm{s}}^{\prime} / b h_{0}$, the following equation is obtained:

$$
\frac{n}{n+1} \xi_{\mathrm{yc}}+\rho^{\prime} \cdot \frac{\varepsilon_{0}\left(\xi_{\mathrm{yc}}-a_{\mathrm{s}}^{\prime} / h_{0}\right)}{f_{\mathrm{c}} \cdot \xi_{\mathrm{yc}}}=\frac{N}{f_{\mathrm{c}} b h_{0}}+\rho \frac{E_{\mathrm{s}} \varepsilon_{0}\left(1-\xi_{\mathrm{yc}}\right)}{f_{\mathrm{c}} \cdot \xi_{\mathrm{yc}}}
$$

where $\xi_{\mathrm{yc}}$ is obtained from equation (19), and the yield curvature of the column section is then calculated according to the geometric similarity relationship.

Owing to the fact that the component stiffness approximates to a constant before the tensile rebars yielding, the curvature distribution of isolated element is similar with a triangular shape bending moment diagram, as shown in Figure 4:

Assuming that $l_{1}=l_{2}=l_{\mathrm{b}} / 2$ and $h_{1}=h_{2}=l_{\mathrm{c}} / 2$, the yield rotation angle of members is obtained according to the distribution above:

$$
\left\{\begin{array}{l}
\theta_{\mathrm{yb}}=\int_{0}^{l_{1(2)}} \varphi_{\mathrm{b}} \mathrm{d} x=\varphi_{\mathrm{yb}} \cdot \frac{l_{1(2)}}{2}=\varphi_{\mathrm{yb}} \cdot \frac{l_{\mathrm{b}}}{4}=\frac{f_{\mathrm{y}} l_{\mathrm{b}}}{4 h_{0}^{\mathrm{b}} E_{\mathrm{s}}\left(1-\xi_{\mathrm{yb}}\right)}, \\
\theta_{\mathrm{yc}}=\int_{0}^{h_{1(2)}} \varphi_{\mathrm{b}} \mathrm{d} x=\varphi_{\mathrm{yc}} \cdot \frac{h_{1(2)}}{2}=\varphi_{\mathrm{yc}} \cdot \frac{l_{\mathrm{c}}}{4}=\frac{f_{\mathrm{c}} l_{\mathrm{c}}}{4 h_{0}^{\mathrm{c}} E_{\mathrm{c}} \xi_{\mathrm{yc}}},
\end{array}\right.
$$

where $h_{0}^{\mathrm{b}}$ and $h_{0}^{\mathrm{c}}$ are the distances from the resultant point of tensile reinforcements to the edge of the compression zone for the beam and column sections, respectively, and $l_{\mathrm{b}}$ and $l_{\mathrm{c}}$ are the structure span and story height, respectively.

As the yield of member sections is equivalent to the initial yield of the longitudinal reinforcements in this study, the rotation angle of beam and column sections under earthquake action can be calculated as follows:

$$
\left\{\begin{array}{c}
\theta_{\mathrm{b}}=\frac{M_{\mathrm{b}} l_{\mathrm{b}}}{4 E_{\mathrm{c}} I_{\mathrm{b}}}, \\
\theta_{\mathrm{c}}=\frac{M_{\mathrm{c}} l_{\mathrm{c}}}{4 E_{\mathrm{c}} I_{\mathrm{c}}},
\end{array}\right.
$$

where $M_{\mathrm{b}}$ and $M_{\mathrm{c}}$ is the moment at the end of the beams and columns, respectively, and $I_{\mathrm{b}}$ and $I_{\mathrm{c}}$ is the inertia moment of the beams and columns, respectively.

By substituting equations (20) and (21) into equation (1), the following equation is obtained: 


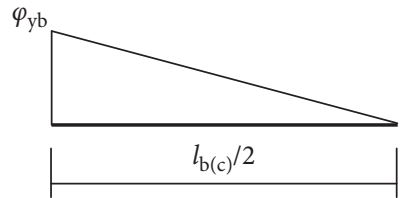

Figure 4: Curvature distribution of members before the tensile rebars yielding.

$$
\left\{\begin{array}{l}
\chi_{\mathrm{b}}=\frac{f_{\mathrm{y}} E_{\mathrm{c}} I_{\mathrm{b}}}{\left(1-\xi_{\mathrm{yb}}\right) M_{\mathrm{b}} h_{0}^{\mathrm{b}} E_{\mathrm{s}}}, \\
\chi_{\mathrm{c}}=\frac{f_{\mathrm{c}} I_{\mathrm{c}}}{\xi_{y c} h_{0}^{\mathrm{c}} M_{\mathrm{c}}} .
\end{array}\right.
$$

Defining the flexural modulus of the beam and column sections as $W_{\mathrm{b}} \approx I_{\mathrm{b}} /\left(h_{0}^{\mathrm{b}} / 2\right)$ and $W_{\mathrm{c}} \approx I_{\mathrm{c}} /\left(h_{0}^{\mathrm{b}} / 2\right)$, respectively, the following relationship is obtained:

$$
\left\{\begin{array}{l}
M_{\mathrm{b}}=\frac{W_{\mathrm{b}} f_{\mathrm{y}} E_{\mathrm{c}}}{2\left(1-\xi_{\mathrm{yb}}\right) \chi_{\mathrm{b}} E_{\mathrm{s}}}, \\
M_{\mathrm{c}}=\frac{W_{\mathrm{c}} f_{\mathrm{c}}}{2 \xi_{\mathrm{yc}} \chi_{\mathrm{c}}}
\end{array}\right.
$$

According to the equilibrium of internal force in joints, $\Sigma M_{\mathrm{b}}=\Sigma M_{\mathrm{c}}$, and the following assumptions-(a) the inflection points of frame beams are located at midspan and those of frame columns are at midheight under the action of lateral load; (b) the cross-sectional size, material strength, and longitudinal reinforcement configuration of beams framing the left and right sides of joints are the same, as well as the plastic deformation under earthquake action; (c) the cross-sectional size, material strength, and longitudinal reinforcement configuration of columns framing the top and bottom sides of joints are the same, as well as the plastic deformation-the following equation is obtained:

$$
\frac{\chi_{\mathrm{c}}}{\chi_{\mathrm{b}}}=\frac{f_{\mathrm{c}} E_{\mathrm{s}}}{f_{\mathrm{y}} E_{\mathrm{c}}} \cdot \frac{W_{\mathrm{c}}}{W_{\mathrm{b}}} \cdot \frac{\Sigma\left(1 / \xi_{\mathrm{yc}}\right)}{\Sigma\left(1 /\left(1-\xi_{\mathrm{yb}}\right)\right)} .
$$

A parameter that reflects the relative relationship between the flexural stiffness of beams and columns is introduced in equation (24) and referred to as the beam-tocolumn linear stiffness ratio:

$$
\frac{\chi_{\mathrm{b}}}{\chi_{\mathrm{c}}}=k \cdot \frac{f_{\mathrm{y}} E_{\mathrm{c}}}{f_{\mathrm{c}} E_{\mathrm{s}}} \cdot \frac{l_{\mathrm{b}} h_{\mathrm{c}}}{l_{\mathrm{c}} h_{\mathrm{b}}} \cdot \frac{\Sigma\left(1 /\left(1-\xi_{\mathrm{yb}}\right)\right)}{\Sigma\left(1 / \xi_{\mathrm{yc}}\right)},
$$

where $k$ is the beam-to-column linear stiffness ratio and $h_{\mathrm{b}}$ and $h_{\mathrm{c}}$ are the section height of the beams and columns, respectively.

If $R_{\chi}=\chi_{\mathrm{b}} / \chi_{\mathrm{c}}$ is defined as the parameter characterizing the sequence of beam and column yielding, a value of less than 1.0 indicates that the structural yielding mechanism of SCWB is achieved during a strong earthquake. $R_{\mathrm{m}}=\left(f_{\mathrm{y}} E_{\mathrm{c}}\right) /$ $\left(f_{\mathrm{c}} E_{\mathrm{y}}\right)$ and $R_{\mathrm{s}}=\left(l_{\mathrm{b}} h_{\mathrm{c}}\right) /\left(l_{\mathrm{c}} h_{\mathrm{b}}\right)$ are defined as the parameters related to material properties and component size, respectively. $R_{\mathrm{k}}=\left[\Sigma 1 /\left(1-\xi_{\mathrm{yb}}\right)\right] /\left(\Sigma 1 / \xi_{\mathrm{yc}}\right)$ is defined as the parameter related to the height of the compression zone, which is mainly concerned with the reinforcement configuration and axial compression ratio as shown in the calculation of $\xi_{\mathrm{yb}}$ and $\xi_{\text {yc }}$.

According to the definitions above, the theoretical limit values of the beam-to-column linear stiffness ratio for achieving the SCWB yielding mechanism are given by

$$
[k]=\frac{1}{R_{\mathrm{s}} \cdot R_{\mathrm{m}} \cdot R_{\mathrm{k}}} .
$$

If $k<[k]$, the SCWB yielding mechanism occurs during an earthquake; otherwise, the strong-beam weak-column yielding mechanism occurs.

2.3. Proposed Limit Values. Equation (26) shows that the SCWB mechanism occurring during an earthquake strongly depends on parameters such as the material strength, component size, member reinforcement ratio, and axial compression ratio. The parameters are assumed as $a_{\mathrm{s}}^{\prime} / h_{0}^{\mathrm{b}(\mathrm{c})} \approx 0.05$ and $n=2.0$ due to the fact that the height of member sections commonly used in practical engineering is generally greater than $600 \mathrm{~mm}$. It is necessary to use tensile and compressive longitudinal reinforcements alternately when calculating the parameter $\xi_{\mathrm{yb}}$ because the force conditions of beams framing the joints are always opposite under earthquake action.

Equations (11) and (19) for calculating the parameters $\xi_{\mathrm{yb}}$ and $\xi_{\mathrm{yc}}$ can be simplified as follows:

$$
\left\{\begin{array}{l}
\xi_{\mathrm{yb}}^{+}+\left(1-\xi_{\mathrm{yb}}^{+}\right) \frac{\varepsilon_{0}}{\varepsilon_{\mathrm{sy}}} \frac{1}{3}\left[\left(1-\frac{\xi_{\mathrm{yb}}^{+}}{1-\xi_{\mathrm{yb}}^{+}} \cdot \frac{\varepsilon_{\mathrm{sy}}}{\varepsilon_{0}}\right)^{3}-1\right]+\rho^{\prime} \cdot \frac{f_{\mathrm{y}}\left(\xi_{\mathrm{yb}}^{+}-0.05\right)}{f_{\mathrm{c}}\left(1-\xi_{\mathrm{yb}}^{+}\right)}=\rho \frac{f_{\mathrm{y}}}{f_{\mathrm{c}}}, \\
\xi_{\mathrm{yb}}^{-}+\left(1-\xi_{\mathrm{yb}}^{-}\right) \frac{\varepsilon_{0}}{\varepsilon_{\mathrm{sy}}} \frac{1}{3}\left[\left(1-\frac{\xi_{\mathrm{yb}}^{-}}{1-\xi_{\mathrm{yb}}^{-}} \cdot \frac{\varepsilon_{\mathrm{sy}}}{\varepsilon_{0}}\right)^{3}-1\right]+\rho \cdot \frac{f_{\mathrm{y}}\left(\xi_{\mathrm{yb}}^{-}-0.05\right)}{f_{\mathrm{c}}\left(1-\xi_{\mathrm{yb}}^{-}\right)}=\rho^{\prime} \frac{f_{\mathrm{y}}}{f_{\mathrm{c}}} \\
\frac{2}{3} \xi_{\mathrm{yc}}+\rho^{\prime} \cdot \frac{\left(\xi_{\mathrm{yc}}-0.05\right)}{E_{\mathrm{c}} \cdot \xi_{\mathrm{yc}}}=\mu_{N}+\rho \frac{E_{\mathrm{s}}\left(1-\xi_{\mathrm{yc}}\right)}{E_{\mathrm{c}} \cdot \xi_{\mathrm{yc}}} .
\end{array}\right.
$$


Practically, the story height of frame structures is $3.0 \mathrm{~m}$, $3.3 \mathrm{~m}, 3.6 \mathrm{~m}, 3.9 \mathrm{~m}$, or $4.2 \mathrm{~m}$, and the span is generally considered to be $4.8 \mathrm{~m}, 5.4 \mathrm{~m}, 6.0 \mathrm{~m}, 6.6 \mathrm{~m}$, or $7.2 \mathrm{~m}$. If we assume $h_{\mathrm{b}} \approx h_{\mathrm{c}}$, the value of $R_{\mathrm{s}}$ ranges from 1.15 to 2.50 . The material strengths involved in equation (27) are valued as follows: HRB335, HRB400, and HRB500 for steel and C30, C35, C40, C45, C50, C55, and C60 for concrete, which are also commonly used in engineering. The limit values of the reinforcement ratio and axial compression ratio for different aseismic grades are clearly specified in current building codes [4]. Based on these specifications, the range of the beam-to-column linear stiffness ratio is calculated as shown in Table 1.

For RC frame structures conforming to the design codes, the SCWB yielding mechanism could not be achieved if the actual beam-to-column linear stiffness ratio in the joint area is larger than the upper limit of $[k]$. In contrast, if the beamto-column linear stiffness ratio is less than the lower limit of $[k]$, the SCWB mechanism occurs under earthquake excitation, independent of the variation in other influencing parameters.

To facilitate practical application, the recommended limit values of the maximum beam-to-column linear stiffness ratio for different aseismic grades are given by reorganizing the data in Table 1, as shown in Table 2.

\section{Experimental Verification of Limit Values}

To verify the limit values of the beam-to-column linear stiffness ratio proposed in this paper, an RC frame building with a regular plane was designed according to the Chinese Code for Seismic Design of Buildings [4]. Considering the lower three-layer substructure of a single frame structure to be a model, two 1/3-scale specimens were constructed and tested under low reversed cyclic loading.

3.1. Specimen Design. The prototype structure was a typical RC moment-resisting frame located in an earthquake-prone region with a seismic fortification intensity of 8 , site soil class II, and design group 1. The longitudinal and horizontal spacing between columns was $6 \mathrm{~m}$ along with a $3.3 \mathrm{~m}$ story height. The section size of columns was designed to $600 \times 600 \mathrm{~mm}$ while that of beams was $300 \times 600 \mathrm{~mm}$; the slab thickness was $100 \mathrm{~mm}$. To investigate the influence of the beam-to-column linear stiffness ratio on the seismic performance of the frame structure, the first-story height was adjusted while the other parameters, such as the cross section of components and the span, remained constant. The comparative frame KJ-2 had a first story height of $4.5 \mathrm{~m}$ with design principles of SCWB, strong-shear weak-flexure, and strong-joint weak-member according to the relevant provisions [4]. Two 1/3-scale models of 3-story, 3-bay RC single frame structures were constructed. The scaled models could accurately reflect the seismic behavior of prototypes, such as the failure pattern, the sequence of plastic hinges, the ultimate bearing capacity, and ultimate deformation capacity, with the method of keeping the reinforcement ratio and material strength constant before and after scaling. The mechanical behavior during the cracking process was difficult to fulfill because the influence factors such as steel diameter and reinforcement ratio as well as relevant variables could not be scaled completely according to geometric similarity, but this shortcoming could be improved through the method adopted above. The commercial concrete used in the test models was $\mathrm{C} 40$ with aggregate size ranging from $5 \mathrm{~mm}$ to $40 \mathrm{~mm}$, and the steel bars were HRB400. The average compressive strength of the $150 \mathrm{~mm}$ concrete cubes was measured as $30.5 \mathrm{MPa}$. Steel bars with nominal diameters of $6 \mathrm{~mm}, 8 \mathrm{~mm}$, and $10 \mathrm{~mm}$ were used as longitudinal reinforcements in the columns and beams, corresponding to actual yield strengths of $471.2 \mathrm{MPa}, 548.9 \mathrm{MPa}$, and 539.2 $\mathrm{MPa}$ and ultimate strengths of $606.2 \mathrm{MPa}, 640.2 \mathrm{MPa}$, and 593.7 $\mathrm{MPa}$, respectively. Additionally, $4 \mathrm{~mm}$ low-carbon steel wire was used as stirrups in both the columns and beams; the actual ultimate strength was $678.6 \mathrm{MPa}$. The geometric dimensions and reinforcement details of the specimens are shown in Figure 5. The major design parameters of each test specimen, such as the axial compression ratio, beam-to-column linear stiffness ratio, and amplification factor, are presented in Table 3.

In this experiment, the frame specimens were constructed without a slab. To avoid the danger caused by heaped loads on the frame beams, the floor loads were converted into vertical concentrated loads and then applied evenly to the top of each column. The axial loads were compensated in time through four manual hydraulic jacks to ensure constant loads throughout the loading process. The test setup and instrumentation are presented in Figure 6.

Lateral low-reversed cyclic loading was applied to the centerline of the top-floor beams in displacement-control mode. The amplitude of each displacement-loading step was determined by the limit values of the interstory drift angle at different performance levels (1/550 for operational, 1/250 for slight damage, 1/120 for medium damage, 1/50 for serious damage, and 1/25 for collapse). The lateral displacement increased from $0 \mathrm{~mm}$ to $18 \mathrm{~mm}$ at an interval of $3 \mathrm{~mm}$ with one loading cycle for each displacement amplitude. After slight damage phenomena occurred, the test specimens entered the plastic stage. Subsequently, three full loading cycles were applied at each displacement amplitude. After structural yielding, the displacement was increased at an increment of $9 \mathrm{~mm}$ until the roof drift angle reached $1 / 26.2$, and the total applied displacement was $126 \mathrm{~mm}$, at which point the test specimens were supposed to collapse. The cyclic loading history is presented in Figure 7.

Two measurement methods were used in the experiment. Traditional data acquisition instruments such as resistance strain gauges and linear variable differential transformers (LVDTs) were placed on the north side of each specimen to measure the interstory displacement and monitor the variation of steel strain during the testing process, as illustrated in Figure 8. Two strain gauges were installed on the longitudinal steel bars at the sections of component ends, and one each on tension and compression side. Strain gauges installed on transverse steel bars were located at each beam-column joint with an interval of $100 \mathrm{~mm}$. LVDTs were used to record the deformation of 
TABLE 1: Range of beam-to-column linear stiffness ratio for different aseismic grades.

\begin{tabular}{|c|c|c|c|c|c|c|c|c|}
\hline \multirow{2}{*}{ Concrete strength } & \multicolumn{2}{|c|}{ Aseismic grade 1} & \multicolumn{2}{|c|}{ Aseismic grade 2} & \multicolumn{2}{|c|}{ Aseismic grade 3} & \multicolumn{2}{|c|}{ Aseismic grade 4} \\
\hline & Minimum & Maximum & Minimum & Maximum & Minimum & Maximum & Minimum & Maximum \\
\hline $\mathrm{C} 30$ & 0.0781 & 0.4854 & 0.0753 & 0.4690 & 0.0672 & 0.4192 & 0.0643 & 0.4009 \\
\hline $\mathrm{C} 35$ & 0.0876 & 0.5811 & 0.0817 & 0.5403 & 0.0728 & 0.4811 & 0.0695 & 0.4595 \\
\hline $\mathrm{C} 40$ & 0.0975 & 0.6693 & 0.0897 & 0.6321 & 0.0794 & 0.5594 & 0.0745 & 0.5249 \\
\hline $\mathrm{C} 45$ & 0.1365 & 0.7625 & 0.1281 & 0.7175 & 0.1127 & 0.6200 & 0.1039 & 0.5715 \\
\hline C50 & 0.1495 & 0.8649 & 0.1372 & 0.7941 & 0.1158 & 0.6706 & 0.1101 & 0.6375 \\
\hline C55 & 0.1657 & 0.9635 & 0.1531 & 0.8813 & 0.1271 & 0.7394 & 0.1206 & 0.7016 \\
\hline C60 & 0.1805 & 1.0837 & 0.1608 & 0.9655 & 0.1348 & 0.8071 & 0.1300 & 0.7787 \\
\hline
\end{tabular}

TABLE 2: Limit values of beam-to-column stiffness ratio.

\begin{tabular}{lccrr}
\hline & \multicolumn{3}{c}{ Aseismic grade } & \multicolumn{1}{c}{3} \\
\hline Beam-to-column linear stiffness ratio & 1 & 2 & 0.65 & 0.60 \\
\hline
\end{tabular}

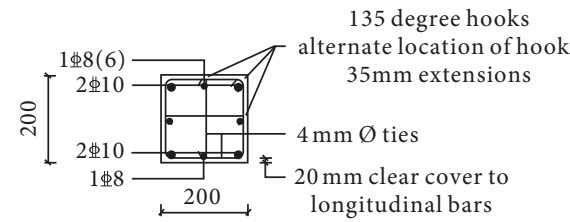

$(1-1(2-2))$

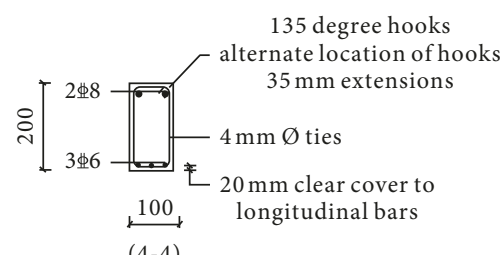

$(4-4)$

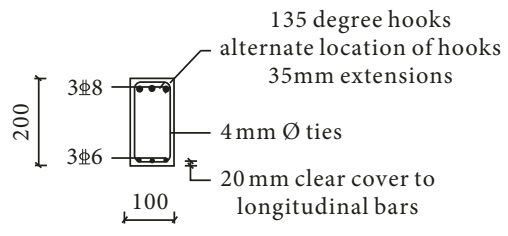

(3-3)

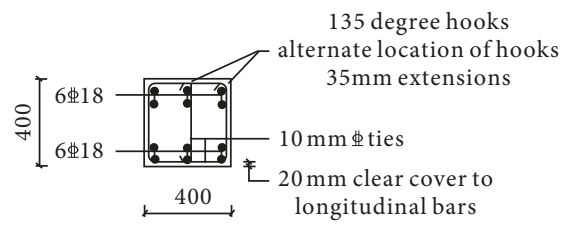

$(5-5)$

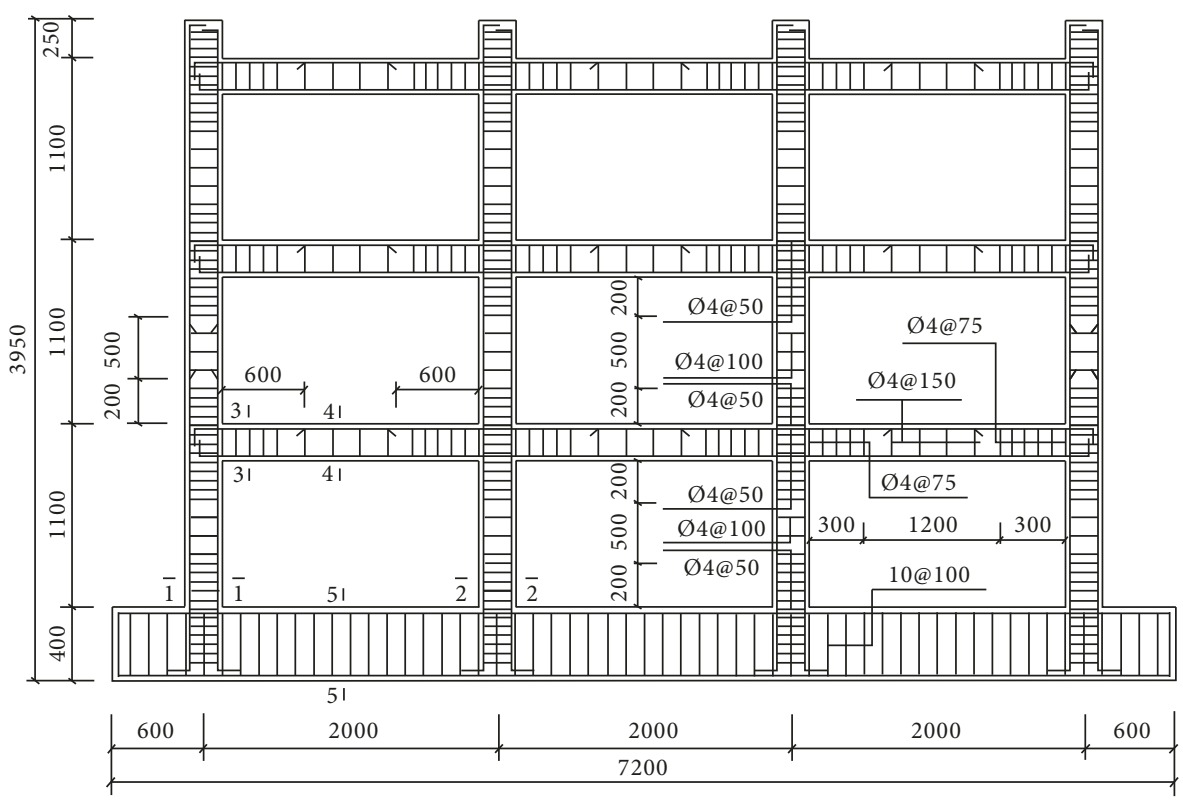

(a)

Figure 5: Continued. 

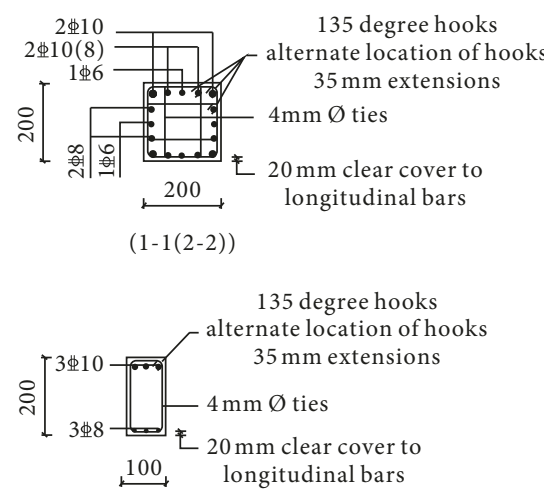

(5-5)

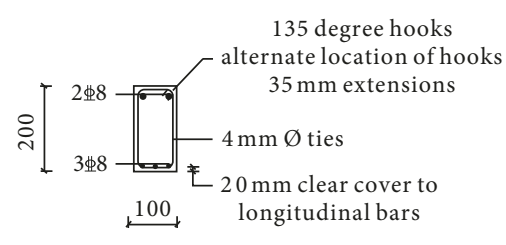

(8-8)
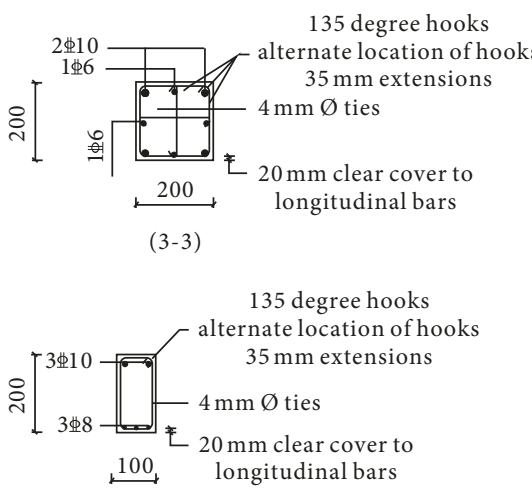

(6-6)

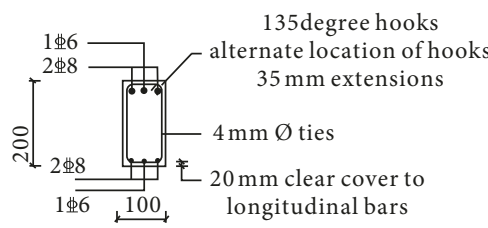

(9-9)

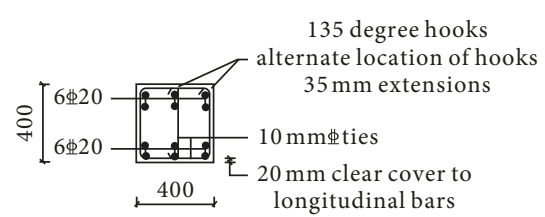

(4-4)

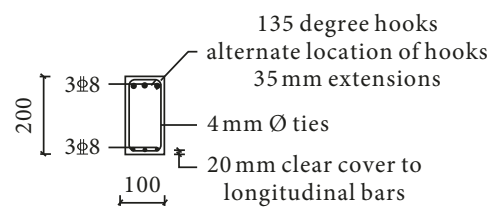

(7-7)

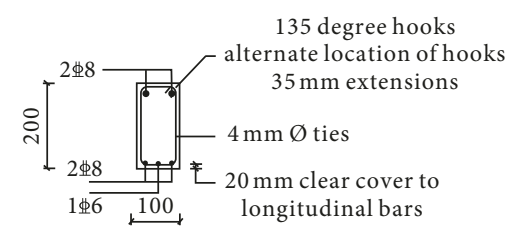

(10-10)

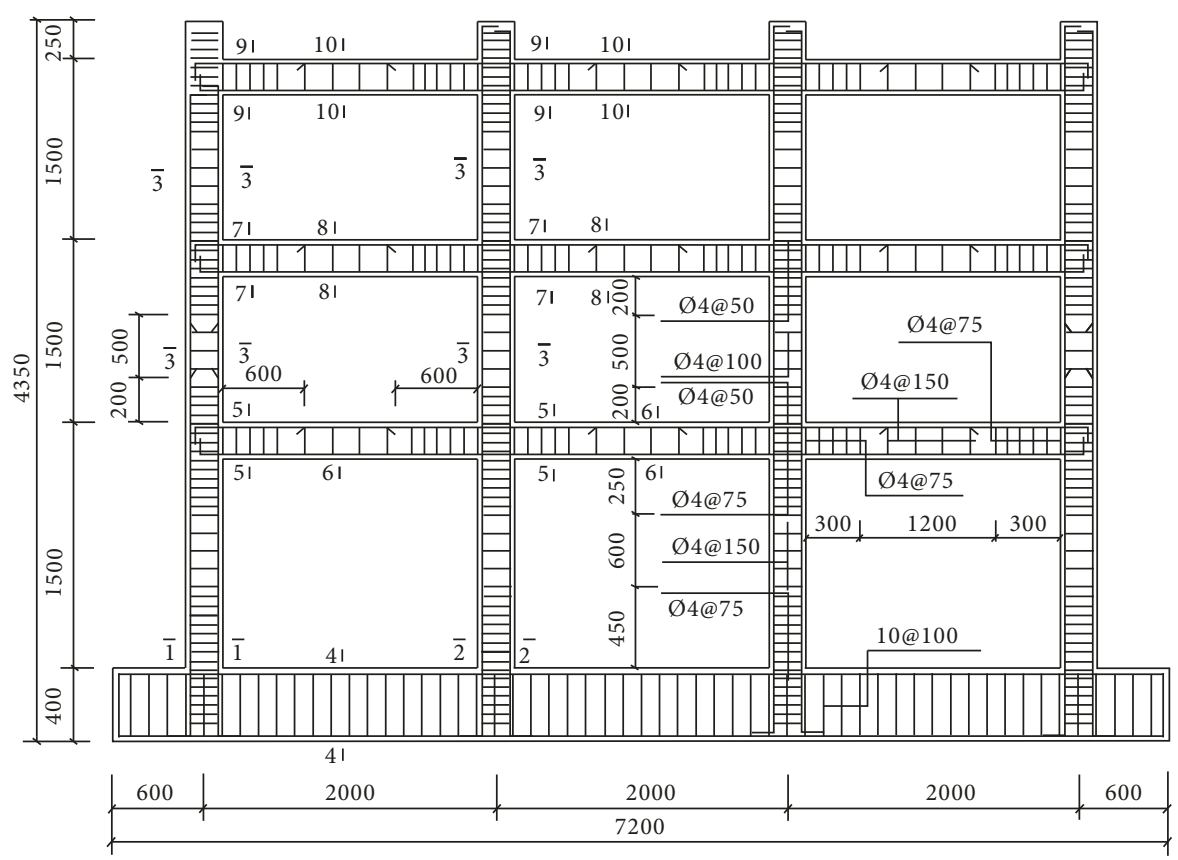

(b)

FIgURE 5: Geometric dimensions and reinforcement details of test specimens. (a) Test setup and reinforcement details of specimen KJ-1. (b) Test setup and reinforcement details of specimen KJ-2.

TABLE 3: Design parameters of test specimens.

\begin{tabular}{|c|c|c|c|c|c|c|c|c|}
\hline \multirow{2}{*}{$\begin{array}{l}\text { Specimen } \\
\text { Joint }\end{array}$} & \multicolumn{4}{|c|}{$\mathrm{KJ}-1$} & \multicolumn{4}{|c|}{$\mathrm{KJ}-2$} \\
\hline & $\mathrm{J}-1$ & $\mathrm{~J}-5$ & $\mathrm{~J}-2$ & $\mathrm{~J}-6$ & $\mathrm{~J}-1$ & $\mathrm{~J}-5$ & $\mathrm{~J}-2$ & $\mathrm{~J}-6$ \\
\hline Axial compression ratio & 0.23 & 0.23 & 0.29 & 0.29 & 0.23 & 0.23 & 0.29 & 0.29 \\
\hline Beam-to-column liner stiffness ratio & 0.27 & 0.27 & 0.54 & 0.54 & 0.37 & 0.27 & 0.74 & 0.54 \\
\hline Amplification factor of flexural capacity & 3.23 & 2.95 & 2.69 & 2.53 & 3.23 & 2.95 & 2.69 & 2.53 \\
\hline
\end{tabular}

Note: J-1 and J-2 are the exterior and interior joints of the first floor of the specimen, respectively, and J-5 and J-6 are the exterior and interior joints of the second floor, respectively. 


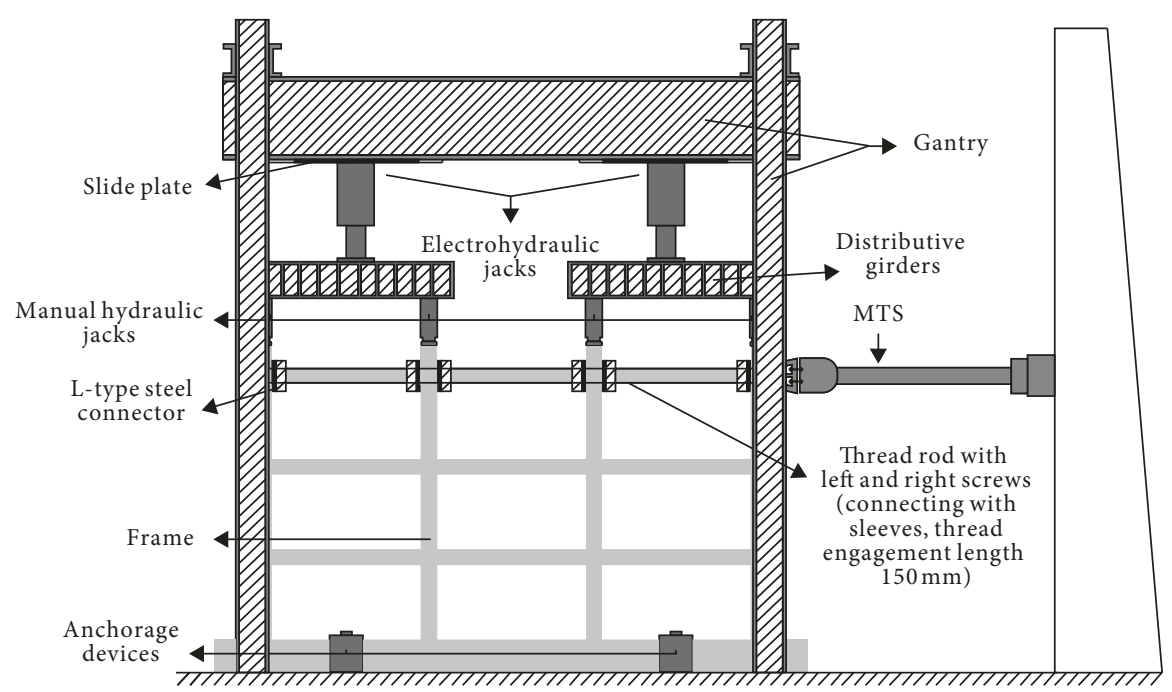

Figure 6: Overview of the test setup.

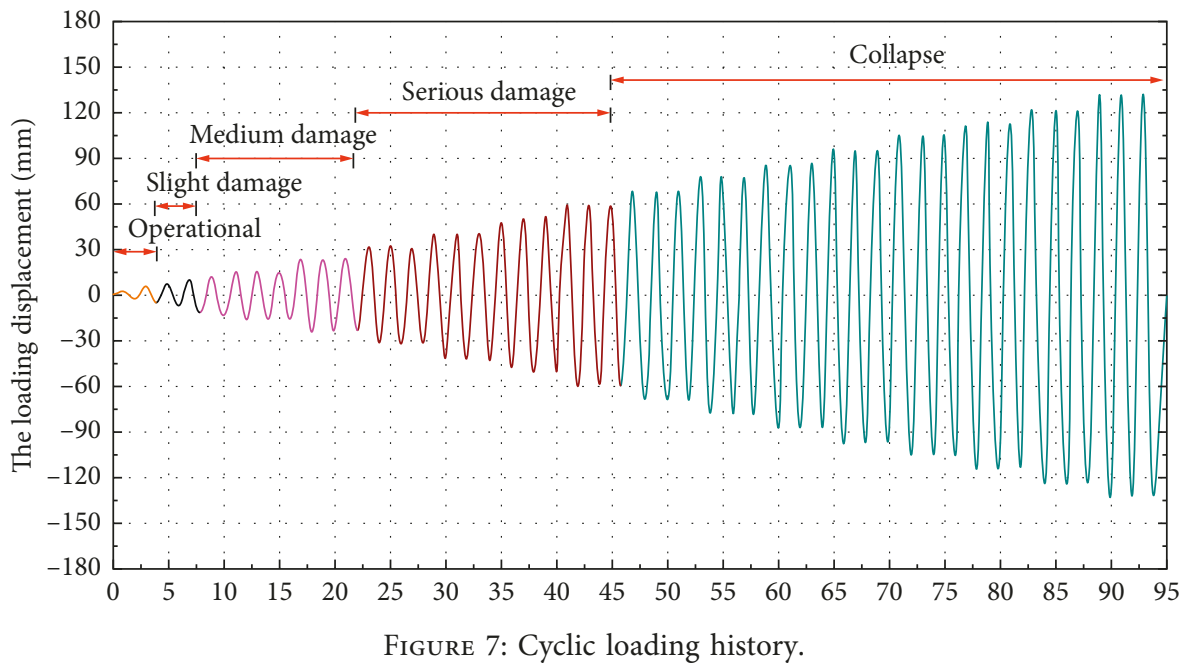

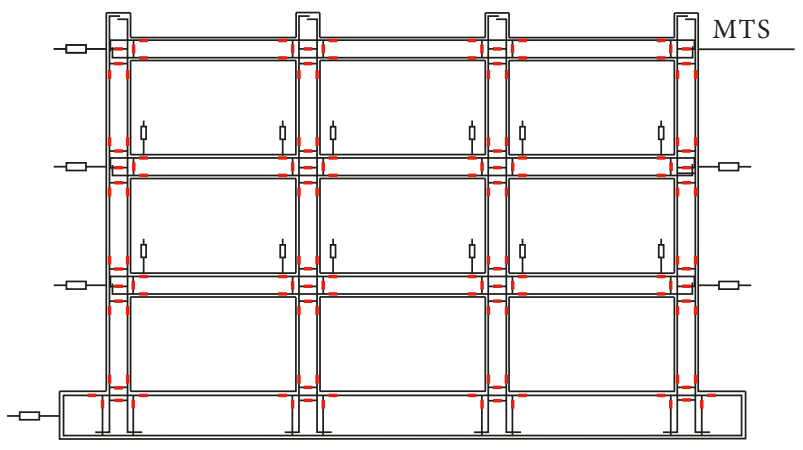

FIgURE 8: Traditional instruments.

members and the displacement at each floor. Two wideranging LVDTs were placed at each floor level and one LVDT was arranged at base beam level to monitor the lateral displacement. LVDTs with lower range were placed vertically at the ends of beams to obtain the beam-to-column relative rotation.
Additionally, digital image correlation (DIC), an emerging noncontact optical technique for measuring displacement and strain [14], was used on the south side of each test frame.

Five high-resolution cameras were used to capture images of the undeformed specimens before loading and subsequent images at each loading step. Furthermore, the open-source software Ncorr-V1.2 [15] was introduced to analyze the acquired digital images and obtain the local deformation of the structural components. The DIC system and speckled pattern are shown in Figure 9.

\subsection{Damage Observation and Failure Mechanism}

3.2.1. Damage Phenomena. Based on the limit values of the interstory drift angle at different performance levels, the test frames were assumed to go through five periods, i.e., operational, slight damage, medium damage, serious damage, and collapse. 


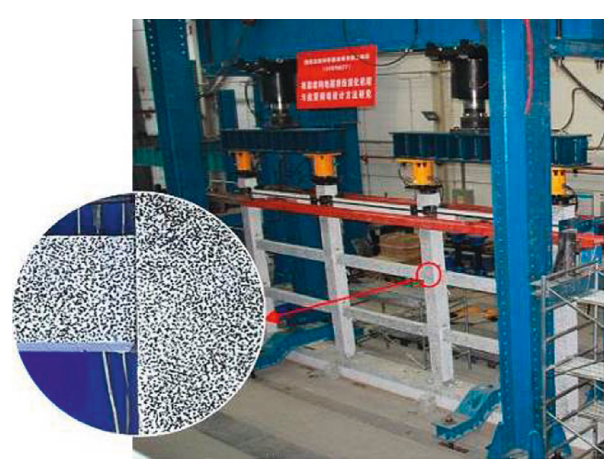

Figure 9: DIC instruments.

At the roof drift ratio of $1 / 1100$, minor flexural cracks first occurred at the beam ends with a maximum width of $0.04 \mathrm{~mm}$. As the roof drift ratio increased to $1 / 550$, the cracks at the beam ends of specimen KJ-1 continued to develop and extended to the midposition, though the number of cracks remained relatively low. However, both the length and number of cracks increased evidently in specimen $\mathrm{KJ}-2$, and the crack widths ranged from $0.06 \mathrm{~mm}$ to $0.12 \mathrm{~mm}$. Most of the cracks were distributed at the beam ends, but few were observed midspan (operational level).

For the two specimens, the average length and width of the cracks at the beam ends increased significantly as the roof drift ratio increased to $1 / 366.5$. The length extended to $5-10 \mathrm{~cm}$ and the width to $0.08-0.24 \mathrm{~mm}$, while a few penetrating cracks formed at the bottoms of the beam ends. New cracks appeared at the bottoms of the first-story columns, but no cracks were detected in the joints during the cycle (slight damage level).

When the roof drift ratio reached $1 / 122.2$, the penetrating cracks at the beam ends increased significantly and the midspan cracks continued to develop with widths ranging from 0.12 to $0.44 \mathrm{~mm}$. Moreover, concrete peeling initiated at the second-story beam-column interface of specimen KJ-1. Cracks at the first-story column bottoms developed, and a small number of penetrating cracks were observed. Even several hair-like cracks aligning with the tops of the beams were detected in the joints. The crack development at the beam ends of specimen KJ-2 was less than that of specimen KJ-1, though cracks at the first-story column bottoms of the former were evident along with numerous penetrating cracks. There were no visible cracks in the joints of specimen $\mathrm{KJ}-2$ at this amplitude (medium damage level).

As the roof drift ratio increased to $1 / 52.4$, small concrete fragments began to fall from the beam ends of specimen KJ1 , exposing the longitudinal reinforcements. Meanwhile, massive penetrating cracks occurred at the first-story column bottoms. Specimen KJ-2 also exhibited severe damage in the form of concrete peeling at the beam ends and firststory column bottoms (serious damage level).

When the roof drift ratio reached 1/36.7, large concrete fragments flaked away from the beam ends and the exposed steel bars began to buckle in specimen KJ-1. A large extent of concrete spalling occurred at the first-story column bottoms, and the longitudinal steel bars and stirrups inside could be observed clearly at the bottom of the interior column on the west side. The damage degree at the beam ends of specimen $\mathrm{KJ}-2$ was slighter than that of specimen $\mathrm{KJ}-1$, and its steel bars were exposed but not buckled. Large concrete fragments flaked away from the column bottoms and the steel bars were exposed. As the roof drift ratio increased to $1 / 33.3$, the exposed longitudinal steel bars at the beam ends buckled and even fractured in the two test specimens. Large amounts of concrete fell off the bottoms of the first-story interior columns. The longitudinal steel bars and stirrups buckled significantly and almost fractured. As the roof drift ratio increased to $1 / 27.7$ for specimen KJ-1 and $1 / 26.2$ for specimen KJ-2, the concrete at the bottoms of the first-story interior columns was crushed to a large scale, and the longitudinal steel bars and stirrups were significantly deformed and subsequently ruptured. Loading was ceased immediately owing to the sudden loss of vertical carrying capacity. The failure phenomena at the end of loading are shown in Figure 10 (collapse level).

3.2.2. Failure Characteristics. According to the failure phenomena descriptions above, the following characteristics can be summarized:

(1) The cracks at the beam ends were mostly distributed in the first $1 / 3$ of the span length and consisted primarily of flexural cracks; few oblique cracks were detected. The longitudinal reinforcements at the beam ends were the first to yield, and the plastic hinges fully developed. The longitudinal steel bars at the beam-column connection interface fractured under the repeated loading due to the uncoordinated deformation between the beams and columns.

(2) Plastic hinges fully developed at the first-story column bottoms, and the energy-dissipation capacity of the steel was exhausted. No plastic hinges developed in the other columns, though flexural cracks formed throughout the total height.

(3) The damage to the beam-column joints was slight, and the steel strain was far from the yield limit, which indicated that the damage was mainly caused by the slippage of the steel bars. 


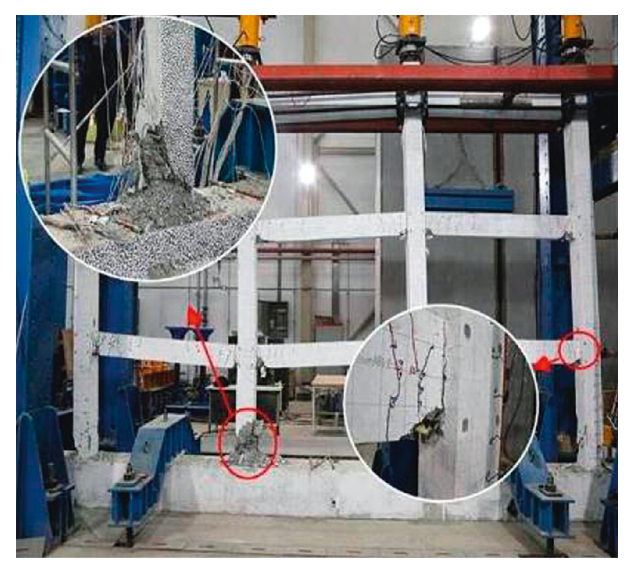

(a)

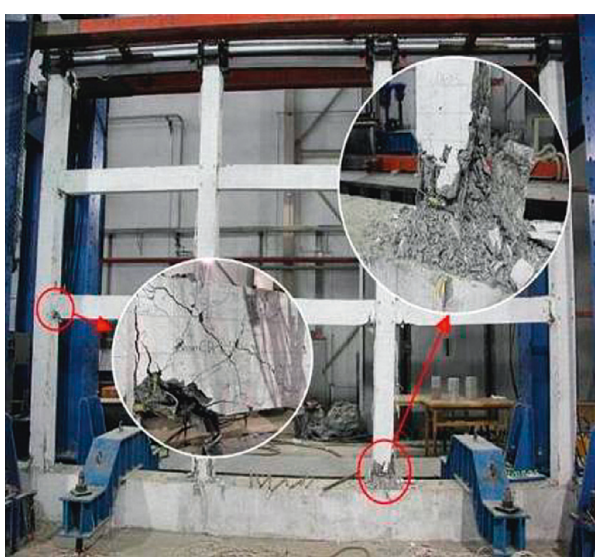

(b)

FIgURE 10: Failure modes of test frames. (a) KJ-1. (b) KJ-2.

(4) Comparing the failure phenomena of specimens KJ1 and $\mathrm{KJ}-2$, it was found that the plastic hinges developed insufficiently at beam ends, but formed easily at the column bottoms in the structures with larger beam-to-column linear stiffness ratios.

3.2.3. Sequence and Distribution of Plastic Hinges. The judgement of a structural failure mode usually depends on the sequence and position of plastic hinges, which were recorded during the testing process. Appearance of plastic hinges is defined as the state that the measured strain exceeds the yield strength of tensile reinforcements, and the results are shown in Figure 11.

The plastic hinges in the columns formed mostly subsequent to those at the beam ends. The failure mode of the two test models was a typical beam-hinge mechanism, owing to the fact that the beam-to-column linear stiffness ratio was mainly affected by the member section sizes, rather than the reinforcement ratios. The test specimens in this study have the same amplification factors, as well as approximate member size; therefore, the plastic hinge formation sequence and final failure mode of the two specimens were almost the same.

3.2.4. Quantitative Judgement of Failure Mode. Merely focusing on the sequence and position of the plastic hinges is a qualitative evaluation of the structural failure mode without quantitative indicators. In this section, a seismic damage model is used to calculate the damage factors and evaluate the damage degree of components under strong earthquake action. Furthermore, the structural failure mode is determined based on the beam-to-column damage ratio.

The local deformation of components can be accurately and directly measured through DIC technology. Thus, the Mehanny-Deierlein model [16] was chosen to quantify the damage degree of members. This model considers the impact of the loading path and has good computational convergence. The damage distribution in the test frames at different performance levels is shown in Figure 12.
The damage of components accumulated as the loading amplitude and cycle number increased and mainly concentrated at the beam ends and column bottoms of the first story at the final collapse. Additionally, the damage indices of the bottom members were generally larger than those of the upper ones: For KJ-1, the average damage index in the first-, second-, and third-floor columns was 0.97, 0.62, and 0.15 , respectively; that of the first-, second-, and third-floor beams was $0.95,0.86$, and 0.74 , respectively, at final collapse. For KJ-2, the average damage index in the first-, second-, and third-floor columns was $0.93,0.65$, and 0.19 , respectively; that of the first-, second-, and third-floor beams was $0.85,0.76$, and 0.59 , respectively.

In terms of the relative damage degrees of the beams and columns, the beam-to-column damage ratio for the first, second, and third floor - the ratio of beams' average damage to columns' average damage on the same floor-was 0.98 , 1.38 , and 4.84, respectively, in specimen KJ-1 and 0.92, 1.16, and 3.08, respectively, in specimen KJ-2. The damage ratios for each floor in specimen KJ-1 were larger than those in specimen KJ-2, which indicates that the damage degree of the beams was more serious than that of the columns in the structures with smaller beam-to-column linear stiffness ratios. It is beneficial to avoid the column-hinge mechanism caused by the concentration of accumulated damage at the columns.

3.3. Verification of Theoretical Limit Values. The validity of the proposed limit values was verified based on the experimental results of the RC plane frames introduced in the previous section. Considering that the structural form and reinforcement configuration were completely symmetrical, and that the interference effect of the loading device on the strength of the members was inevitable, only the joints of the first and second stories (J-1, J-2, J-5, and J-6) were studied. The results are presented in Table 4 .

The results in Table 4 are generally consistent with the theoretical results in Table 2, which indicates that the governing equation of the structural yielding mechanism 


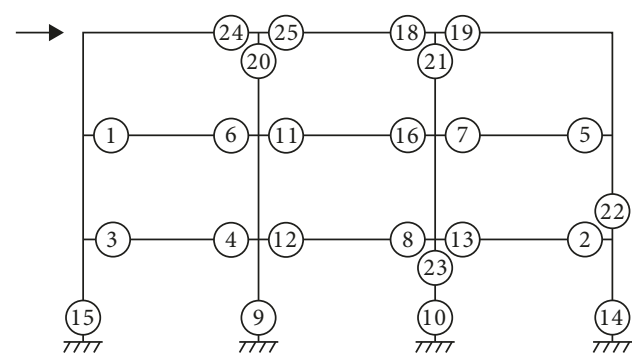

(a)

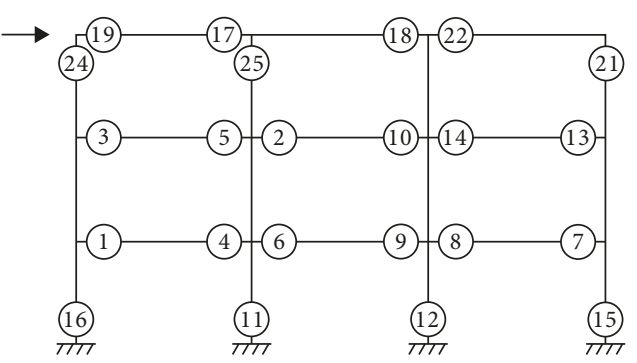

(b)

FIGURE 11: Sequence and position of plastic hinges in test specimens. (a) KJ-1. (b) KJ-2.

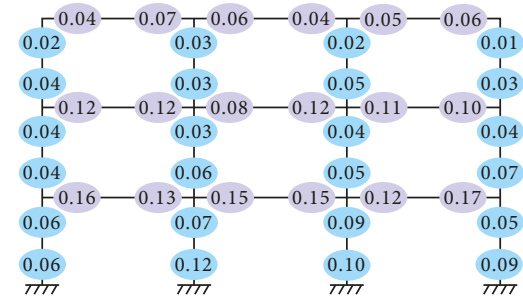

(A) Operational $(\mathrm{IDR}=1 / 550)$

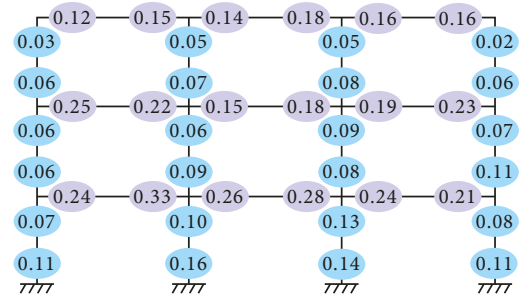

(B) Slight damage $($ IDR $=1 / 360)$

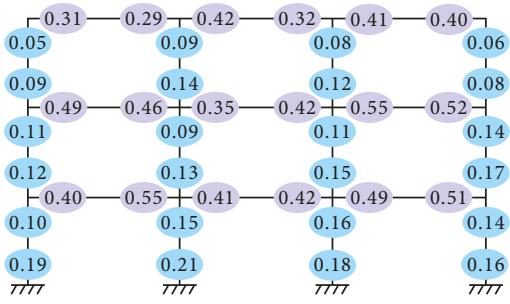

(C) Medium damage $($ IDR $=1 / 120)$

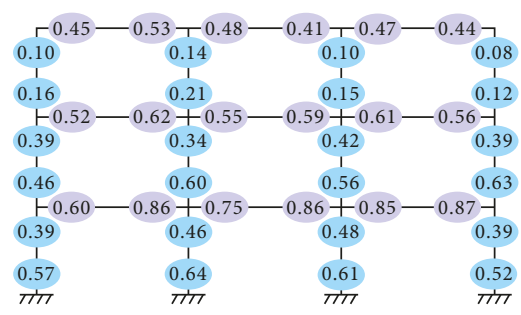

(D) Serious damage (IDR $=1 / 50)$

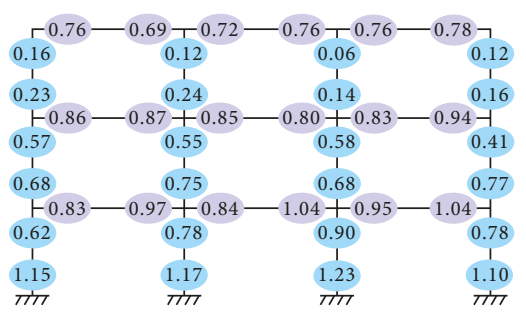

(E) Collapse $($ IDR $=1 / 28)$

(a)

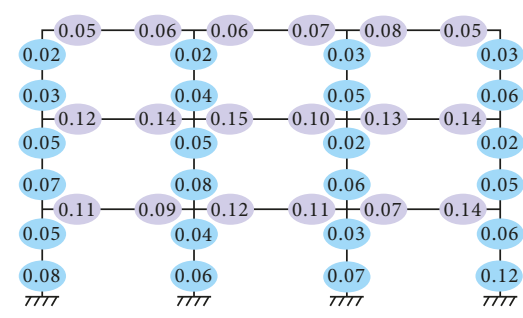

(A) Operational $(\mathrm{IDR}=1 / 550)$

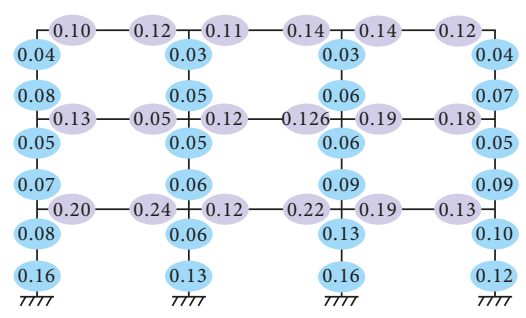

(B) Slight damage $($ IDR $=1 / 360)$

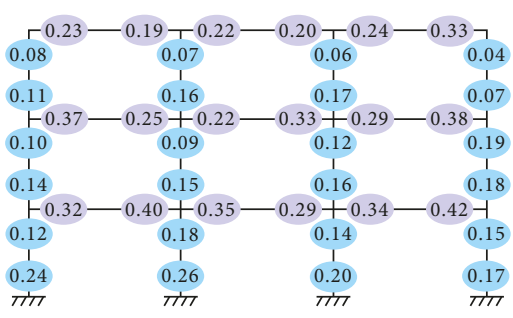

(C) Medium damage $($ IDR $=1 / 120)$

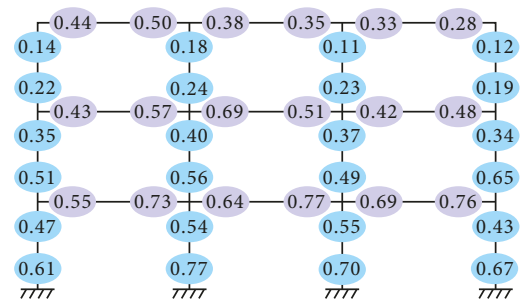

(D) Serious damage (IDR $=1 / 50)$

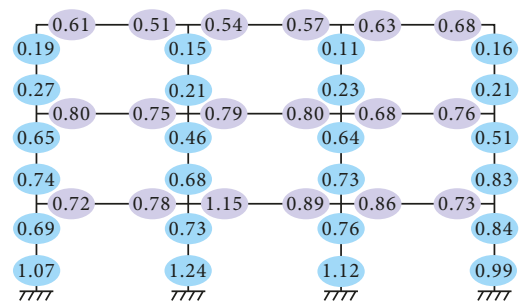

(E) Collapse $($ IDR $=1 / 26)$

(b)

Figure 12: Damage distribution of test frames. (a) KJ-1. (b) KJ-2. 
TABLE 4: Comparison of experimental phenomena and theoretical judgement.

\begin{tabular}{|c|c|c|c|c|c|c|c|c|c|c|}
\hline \multicolumn{2}{|c|}{ Frame joints } & $B \times h(\mathrm{~mm})$ & $A_{\mathrm{s}}^{\prime}\left(\mathrm{mm}^{2}\right)$ & $A_{\mathrm{s}}\left(\mathrm{mm}^{2}\right)$ & $I_{0}\left(\mathrm{~mm}^{4}\right)$ & $L(\mathrm{~mm})$ & {$[k]_{\max }$} & $k$ & Experimental results & Theoretical results \\
\hline KJ1-J1 & $\begin{array}{l}\text { Beam } \\
\text { Column }\end{array}$ & $\begin{array}{l}100 \times 200 \\
200 \times 200\end{array}$ & $\begin{array}{l}150.79 \\
207.34\end{array}$ & $\begin{array}{c}84.82 \\
207.34\end{array}$ & $\begin{array}{l}2.61 \times 10^{8} \\
5.23 \times 10^{8}\end{array}$ & $\begin{array}{l}2000 \\
1100\end{array}$ & 0.75 & 0.27 & Beam hinge & Beam hinge \\
\hline KJ1-J2 & $\begin{array}{c}\text { Beam } \\
\text { Column }\end{array}$ & $\begin{array}{l}100 \times 200 \\
200 \times 200\end{array}$ & $\begin{array}{l}150.79 \\
185.35\end{array}$ & $\begin{array}{c}84.82 \\
185.35 \\
\end{array}$ & $\begin{array}{l}2.61 \times 10^{8} \\
5.25 \times 10^{8}\end{array}$ & $\begin{array}{l}2000 \\
1100\end{array}$ & 0.75 & 0.27 & Beam hinge & Beam hinge \\
\hline KJ1-J5 & $\begin{array}{c}\text { Beam } \\
\text { Column }\end{array}$ & $\begin{array}{l}100 \times 200 \\
200 \times 200\end{array}$ & $\begin{array}{l}150.79 \\
185.35 \\
\end{array}$ & $\begin{array}{c}84.82 \\
185.35\end{array}$ & $\begin{array}{l}2.61 \times 10^{8} \\
5.25 \times 10^{8}\end{array}$ & $\begin{array}{l}2000 \\
1100\end{array}$ & 0.75 & 0.27 & Beam hinge & Beam hinge \\
\hline KJ1-J6 & $\begin{array}{c}\text { Beam } \\
\text { Column }\end{array}$ & $\begin{array}{l}100 \times 200 \\
200 \times 200\end{array}$ & $\begin{array}{l}150.79 \\
185.35\end{array}$ & $\begin{array}{c}84.82 \\
185.35\end{array}$ & $\begin{array}{l}2.61 \times 10^{8} \\
5.25 \times 10^{8}\end{array}$ & $\begin{array}{l}2000 \\
1100\end{array}$ & 0.75 & 0.27 & Beam hinge & Beam hinge \\
\hline KJ2-J1 & $\begin{array}{c}\text { Beam } \\
\text { Column }\end{array}$ & $\begin{array}{l}100 \times 200 \\
200 \times 200\end{array}$ & $\begin{array}{l}235.61 \\
342.42 \\
\end{array}$ & $\begin{array}{l}150.79 \\
342.42 \\
\end{array}$ & $\begin{array}{l}2.58 \times 10^{8} \\
5.18 \times 10^{8} \\
\end{array}$ & $\begin{array}{l}2000 \\
1500 \\
\end{array}$ & 0.75 & 0.37 & Beam hinge & Beam hinge \\
\hline KJ2-J2 & $\begin{array}{c}\text { Beam } \\
\text { Column }\end{array}$ & $\begin{array}{l}100 \times 200 \\
200 \times 200\end{array}$ & $\begin{array}{l}235.61 \\
285.88 \\
\end{array}$ & $\begin{array}{l}150.79 \\
285.88 \\
\end{array}$ & $\begin{array}{l}2.58 \times 10^{8} \\
5.21 \times 10^{8} \\
\end{array}$ & $\begin{array}{l}2000 \\
1500 \\
\end{array}$ & 0.75 & 0.37 & Beam hinge & Beam hinge \\
\hline KJ2-J5 & $\begin{array}{c}\text { Column } \\
\text { Beam }\end{array}$ & $\begin{array}{l}100 \times 200 \\
200 \times 200\end{array}$ & $\begin{array}{l}150.79 \\
185.35 \\
\end{array}$ & $\begin{array}{l}150.79 \\
185.35 \\
\end{array}$ & $\begin{array}{l}2.60 \times 10^{8} \\
5.25 \times 10^{8} \\
\end{array}$ & $\begin{array}{l}2000 \\
1100 \\
\end{array}$ & 0.75 & 0.27 & Beam hinge & Beam hinge \\
\hline KJ2-J6 & $\begin{array}{c}\text { Column } \\
\text { Beam }\end{array}$ & $\begin{array}{l}100 \times 200 \\
200 \times 200\end{array}$ & $\begin{array}{l}150.79 \\
185.35 \\
\end{array}$ & $\begin{array}{l}150.79 \\
185.35\end{array}$ & $\begin{array}{l}2.60 \times 10^{8} \\
5.25 \times 10^{8}\end{array}$ & $\begin{array}{l}2000 \\
1100\end{array}$ & 0.75 & 0.27 & Beam hinge & Beam hinge \\
\hline
\end{tabular}

Note: $A_{\mathrm{s}}^{\prime}$ is the cross-sectional area of compressive reinforcements; $A_{\mathrm{s}}$ is the cross-sectional area of tensile reinforcements; $I_{0}$ is the inertia moment of components; $l$ is the effective length of components. In this study, the sectional area of the steel bars was converted into that of the concrete material with the effective inertia moment during the calculation of the components' inertia moment. The beam-to-column linear stiffness ratio is defined as the ratio of elastic linear stiffness, without considering the different calculation methods between the exterior and interior joints. Additionally, the beam-to-column linear stiffness ratio of the interior joints was reduced by half when comparing it with the theoretical limit values in the table above, based on the fact that the crosssectional sizes and reinforcement configurations of beams framing the same joints were identical.

had a certain feasibility in improving the SCWB design philosophy.

\section{Applicability of Beam-to-Column Linear Stiffness Ratio}

Previous surveys on earthquake disasters have showed that structural damage is mainly concentrated at column ends, while few plastic hinges form at the beams. These phenomena indicate that solely enhancing the flexural strength of columns is insufficient to control the structural failure mode; that is, the relative stiffness of beams to columns should not be neglected. In this section, six 6-story, 3-span plane frames are designed according to different seismic fortification intensities and the effect of the relative stiffness of beams to columns on the achievement of the beam-hinge mechanism is studied by comparing the elastoplastic timehistory analysis results of numerical models with and without the consideration of the beam-to-column linear stiffness ratio limit values.

4.1. Case Design. The plane layout, story height, span length, and slab thickness in the numerical examples were the same as the prototype structure (a 6-story, 3-span RC building). The sectional sizes and reinforcement details of members were readjusted according to the seismic fortification intensity to meet the requirements of bearing capacity and plastic deformation under seismic excitation. Single-plane frames in the structure were selected as the research objects, and the plastic hinge rates and curvature ductility coefficients of the beams and columns were taken as evaluation indicators to decide the structural failure mode. Numerical models of 6-degree $(0.05 \mathrm{~g}), 7$-degree $(0.10 \mathrm{~g}), 7$-degree $(0.15 \mathrm{~g}), 8$-degree $(0.20 \mathrm{~g}), 8$-degree $(0.30 \mathrm{~g})$, and 9-degree $(0.40 \mathrm{~g})$ seismic intensity were denoted $\mathrm{KJ} 1, \mathrm{KJ} 2, \mathrm{KJ} 3, \mathrm{KJ} 4$, $\mathrm{KJ} 5$, and KJ6, respectively. The sectional sizes and reinforcement details are shown in Table 5.

A plane frame is mainly composed of beams and columns; thus, the fiber-beam element B31 was selected to establish the numerical model. The beam properties were defined for a rectangular cross-sectional shape. Each section was divided into multifiber bundles with the uniaxial stressstrain relationship of concrete material imparted to each fiber. Steel reinforcements were inserted into each element using the keyword $*$ REBAR to ensure the computational convergence and improve the computational efficiency [17], as shown in Figure 13. The keyword $*$ Transverse Shear Stiffness was also used to define the transverse shear stiffness of each section.

The material constitutive models were simulated using the PQ-Fiber subroutine [18] through the converter program UMAT. UConcrete 02 was used as the concrete material to consider the confined effect of the stirrups on the strength and ductility. It is an isotropic elastoplastic concrete material defined by a modified Kent-Park model $[19,20]$ as the compression constitutive relation and the bilinear model with a softening segment as the tension constitutive relation, as shown in Figure 14. Usteel02 was used as the steel material to consider the Bauschinger effect caused by stiffness degradation. It is the improved form of the proposed maximum point-oriented bilinear model [21], as shown in Figure 15.

According to the relevant provisions in seismic design code, the average response spectrum of the selected seismic recordings should be statistically in accordance with the design response spectrum adopted in the mode- 
TABle 5: Design parameters of numerical models (not considering the limit values in Table 2).

\begin{tabular}{|c|c|c|c|c|c|c|c|}
\hline \multirow{2}{*}{ Frame } & \multirow{2}{*}{ Component type } & \multirow{2}{*}{ Sectional size } & \multirow{2}{*}{ Floor } & \multicolumn{2}{|c|}{ Reinforcement details } & \multirow{2}{*}{$k$} & \multirow{2}{*}{ Amplification factors } \\
\hline & & & & Interior & Exterior & & \\
\hline \multirow{2}{*}{ KJ1 } & Beams & $250 \times 600$ & $1-6$ & $4 \$ 14(2 \phi 18)$ & $4 \$ 14(2 \$ 18)$ & 0674 & 5551 \\
\hline & Columns & $550 \times 550$ & $1-6$ & \multicolumn{2}{|c|}{$4 \$ 16+8 \Phi 14$} & $0.6 / 4$ & 5.551 \\
\hline \multirow{4}{*}{ KJ2 } & \multirow{3}{*}{ Beams } & \multirow{3}{*}{$300 \times 600$} & $1-4$ & $2 \phi 16+2 \phi 14(3 \phi 14)$ & $4 \$ 16(3 \phi 14)$ & \multirow{4}{*}{0.792} & \multirow{4}{*}{5.052} \\
\hline & & & 5 & \multicolumn{2}{|c|}{$4 \Phi 14(3 \Phi 14)$} & & \\
\hline & & & 6 & $3 \phi 14(3 \phi 14)$ & $3 \phi 14(3 \phi 14)$ & & \\
\hline & Columns & $550 \times 550$ & $1-6$ & \multicolumn{2}{|l|}{$12 \$ 16$} & & \\
\hline \multirow{4}{*}{ KJ3 } & \multirow{3}{*}{ Beams } & \multirow{3}{*}{$300 \times 600$} & $1-4$ & $2 \phi 18+2 \phi 16(3 \phi 14)$ & $4 \phi 18(3 \phi 14)$ & \multirow{4}{*}{0.803} & \multirow{4}{*}{4.323} \\
\hline & & & 5 & $3 \phi 16(3 \phi 14)$ & $2 \phi 16+2 \phi 14(3 \phi 14)$ & & \\
\hline & & & 6 & \multicolumn{2}{|c|}{$3 \phi 14(3 \phi 14)$} & & \\
\hline & Columns & $550 \times 550$ & $1-6$ & \multicolumn{2}{|l|}{$12 \$ 16$} & & \\
\hline \multirow{5}{*}{ KJ4 } & \multirow{3}{*}{ Beams } & \multirow{3}{*}{$300 \times 600$} & $1-4$ & $2 \phi 20+2 \phi 18(3 \phi 16)$ & $4 \$ 20(3 \$ 16)$ & & \\
\hline & & & 5 & $4 \$ 16(3 \phi$ & & & \\
\hline & & & 6 & $4 \phi 14(3 \phi$ & & 0.816 & 3.631 \\
\hline & \multirow{2}{*}{ Columns } & \multirow{2}{*}{$550 \times 550$} & 1 & \multirow{2}{*}{\multicolumn{2}{|c|}{$\begin{array}{c}4 \Phi 20+4 \Phi 20+4 \$ 18 \\
4 \$ 18+8 \Phi 16\end{array}$}} & & \\
\hline & & & $2-6$ & & & & \\
\hline & & & $1-4$ & $2 \phi 25+2 \Phi 20(2 \phi 18+2 \phi 16)$ & $2 \Phi 25+2 \Phi 20(4 \$ 18)$ & & \\
\hline & Beams & $300 \times 600$ & 5 & $4 \phi 18+4 \phi$ & & & \\
\hline & & & 6 & $4 \$ 16+4 \phi$ & & & \\
\hline KI5 & & & 1 & $4 \phi 25+8 \Phi 20$ & $12 \$ 25$ & 0832 & 2787 \\
\hline (1) & & & 2 & $4 \phi 20+8 \Phi 18$ & $4 \Phi 22+4 \Phi 20+4 \Phi 18$ & 0.832 & 2.781 \\
\hline & Columns & $550 \times 550$ & 3 & $12 \$ 20$ & $4 \Phi 22+4 \Phi 20+4 \Phi 18$ & & \\
\hline & & & 4 & $12 \Phi 20$ & $4 \$ 20+8 \$ 18$ & & \\
\hline & & & $5-6$ & $12 \Phi 20$ & $12 \Phi 20$ & & \\
\hline & & & $1-4$ & $4 \$ 25(2 \phi 22+2 \phi 20)$ & $2 \phi 25+2 \phi 20(4 \phi 22)$ & & \\
\hline & Beams & $300 \times 650$ & 5 & $2 \$ 20+2 \$ 18(4 \$ 16$ & $2 \phi 20+2 \phi 18(4 \phi 16)$ & & \\
\hline & & & 6 & $4 \$ 16(4 \$$ & & & \\
\hline & & & 1 & $24 \$ 25$ & $4 \phi 28+8 \Phi 28+8 \phi 25$ & & \\
\hline KJ6 & & & 2 & $18 \$ 25$ & $4 \$ 25+8 \Phi 25+4 \Phi 20$ & 0.974 & 2.612 \\
\hline & Columns & $550 \times 550$ & 3 & $4 \Phi 25+6 \Phi 25+6 \Phi 22$ & $4 \Phi 25+8 \Phi 25+4 \Phi 20$ & & \\
\hline & & & 4 & $14 \$ 25$ & $4 \phi 25+6 \Phi 25+4 \Phi 20$ & & \\
\hline & & & $5-6$ & $12 \phi 20$ & & & \\
\hline
\end{tabular}

Note: $4 \$ 14$ (2\$18) indicates that the upper and lower reinforcements of the beam section are $4 \$ 14$ and $2 \$ 18$, respectively.

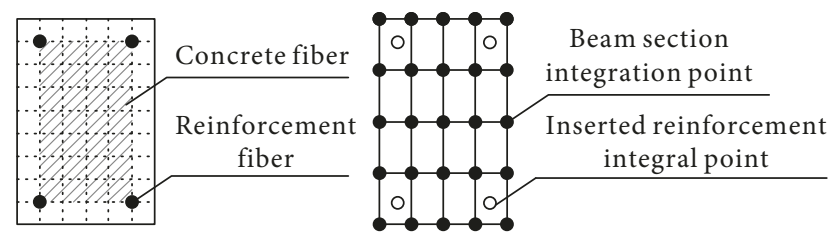

FIGURE 13: Section of fiber-beam element.

decomposition method. As such, five ground motion records that were similar to the design response spectrum were selected for the elastoplastic time-history analysis based on the fact that the seismic amplitude scaling needs to be performed according to the seismic fortification intensity. The difference between the average response spectrum and design response spectrum was $13.33 \%$ and $18.92 \%$ in the controlling bands of $\left[0.1, T_{\mathrm{g}}\right]$ and $\left[T_{1}-0.2, T_{1}+0.5\right]$, respectively, as shown in Figure 16. Thus, it generally meets the requirements of the dual-frequency-domain controlling method [22].

4.2. Structural Failure Mode without considering Limit Values. The selected ground motion records were applied in the numerical models $\mathrm{KJ} 1-\mathrm{KJ} 6$, and the structural failure modes were then determined according to the plastic hinge distribution.

4.2.1. Plastic Hinge Rates of Beams and Columns. The plastic hinge rates of the beams and columns are defined by the proportion of plastic hinges at the beam or column ends to the total number of structural members. The plastic hinge rates of the beams and columns in models KJ1-KJ6 are shown in Tables 6-11. It can be seen from the tables above that the plastic hinge rates of the beams were always larger than those of the columns for frame structures with different seismic fortification intensities. However, the values of these two parameters tend to become identical gradually as the peak ground acceleration increases. Hence, the structures have the potential to collapse due to the excessive formation of plastic hinges at the column ends when subjected to earthquake action stronger than the design fortification intensity. It is noteworthy that the plastic hinge rates of the beams and columns were relatively low for model KJ1 with 6 -degree $(0.05 \mathrm{~g})$ seismic intensity because the structure was not seriously damaged and most of the members were still in the elastic range under the low peak ground acceleration 


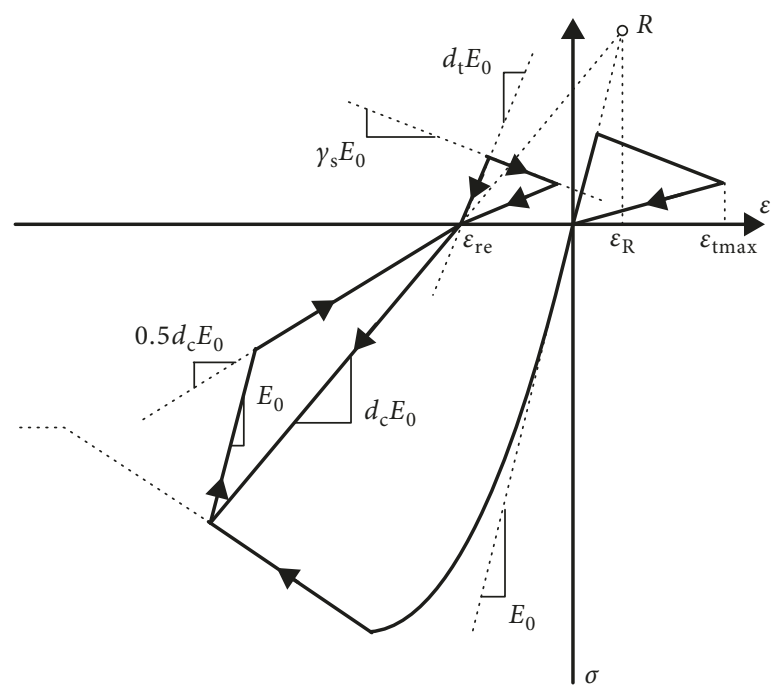

FIgURE 14: Constitutive model of concrete material.

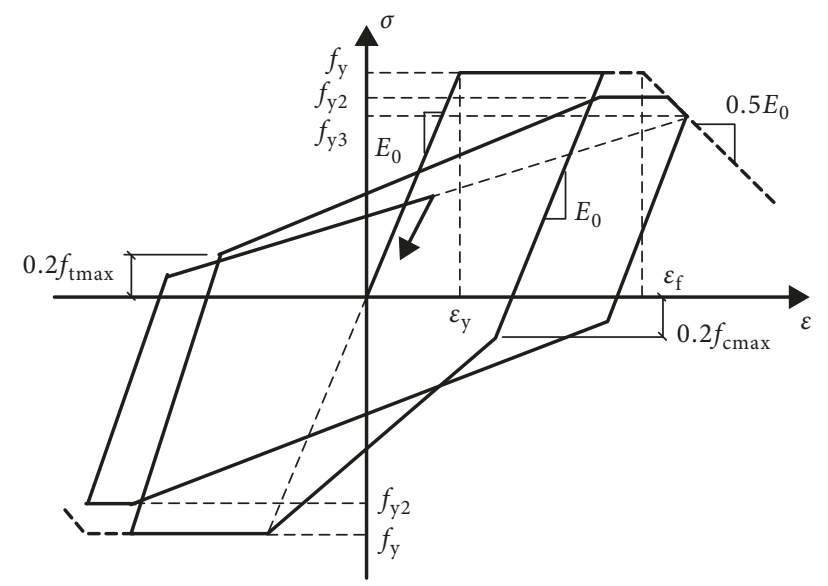

FIGURE 15: Constitutive model of steel material.

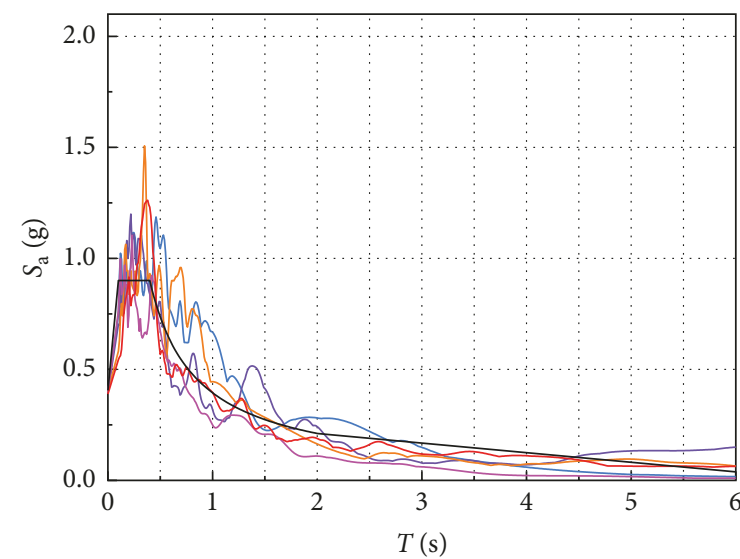

— Northwest Calif. 02/09/1941

— Hollister 03/24/1974

_ Imperial Valley 5/19/1940

— Parkfield 06/28/1966

— San Fernando 02/09/1971

— Design response spectrum

(a)

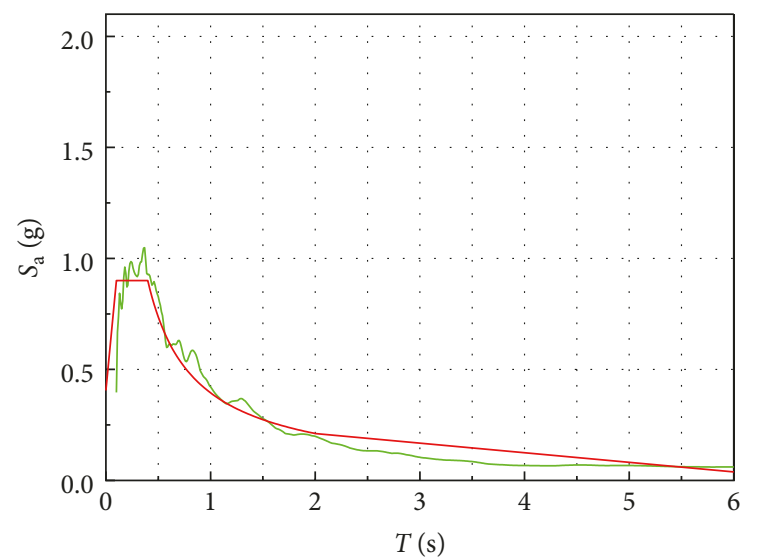

- Average response spectrum

_ Design response spectrum

FIGURE 16: Response spectra of selected seismic waves. (a) Comparison of selected seismic wave and design response spectra. (b) Comparison of average and design response spectra. 
TABLe 6: Plastic hinge rates of beams and columns in model KJ1.

\begin{tabular}{|c|c|c|c|c|c|}
\hline Specimen & Selected seismic waves & $P_{\mathrm{c}}$ & Average & $P_{\mathrm{b}}$ & Average \\
\hline \multirow{5}{*}{ KJ1 } & Northwest Calif. 02/09/1941 & 0.08 & \multirow{5}{*}{0.15} & 0.11 & \multirow{5}{*}{0.28} \\
\hline & Hollister $03 / 24 / 1974$ & 0.13 & & 0.28 & \\
\hline & Imperial Valley 5/19/1940 & 0.21 & & 0.33 & \\
\hline & Parkfield 06/28/1966 & 0.21 & & 0.39 & \\
\hline & San Fernando 02/09/1971 & 0.13 & & 0.28 & \\
\hline
\end{tabular}

Note: $P_{\mathrm{c}}$ is the plastic hinge rate of columns and $P_{\mathrm{b}}$ is the plastic hinge rate of beams.

TABle 7: Plastic hinge rates of beams and columns in model KJ2.

\begin{tabular}{|c|c|c|c|c|c|}
\hline Specimen & Selected seismic waves & $P_{\mathrm{c}}$ & Average & $P_{\mathrm{b}}$ & Average \\
\hline \multirow{5}{*}{ KJ2 } & Northwest Calif. 02/09/1941 & 0.08 & \multirow{5}{*}{0.19} & 0.22 & \multirow{5}{*}{0.38} \\
\hline & Hollister 03/24/1974 & 0.17 & & 0.39 & \\
\hline & Imperial Valley 5/19/1940 & 0.21 & & 0.44 & \\
\hline & Parkfield 06/28/1966 & 0.25 & & 0.28 & \\
\hline & San Fernando 02/09/1971 & 0.25 & & 0.56 & \\
\hline
\end{tabular}

TABLE 8: Plastic hinge rates of beams and columns in model KJ3.

\begin{tabular}{|c|c|c|c|c|c|}
\hline Specimen & Selected seismic waves & $P_{\mathrm{c}}$ & Average & $P_{\mathrm{b}}$ & Average \\
\hline \multirow{5}{*}{$\mathrm{KJ} 3$} & Northwest Calif. 02/09/1941 & 0.17 & \multirow{5}{*}{0.30} & 0.39 & \multirow{5}{*}{0.53} \\
\hline & Hollister 03/24/1974 & 0.21 & & 0.56 & \\
\hline & Imperial Valley 5/19/1940 & 0.33 & & 0.39 & \\
\hline & Parkfield 06/28/1966 & 0.42 & & 0.56 & \\
\hline & San Fernando 02/09/1971 & 0.38 & & 0.78 & \\
\hline
\end{tabular}

TABLE 9: Plastic hinge rates of beams and columns in model KJ4.

\begin{tabular}{|c|c|c|c|c|c|}
\hline Specimen & Selected seismic waves & $P_{c}$ & Average & $P_{\mathrm{b}}$ & Average \\
\hline \multirow{5}{*}{ KJ4 } & Northwest Calif. 02/09/1941 & 0.25 & \multirow{5}{*}{0.38} & 0.44 & \multirow{5}{*}{0.61} \\
\hline & Hollister 03/24/1974 & 0.33 & & 0.61 & \\
\hline & Imperial Valley 5/19/1940 & 0.46 & & 0.56 & \\
\hline & Parkfield 06/28/1966 & 0.38 & & 0.67 & \\
\hline & San Fernando 02/09/1971 & 0.50 & & 0.78 & \\
\hline
\end{tabular}

TABle 10: Plastic hinge rates of beams and columns in model KJ5.

\begin{tabular}{|c|c|c|c|c|c|}
\hline Specimen & Selected seismic waves & $P_{\mathrm{c}}$ & Average & $P_{\mathrm{b}}$ & Average \\
\hline \multirow{5}{*}{ KJ5 } & Northwest Calif. 02/09/1941 & 0.42 & \multirow{5}{*}{0.44} & 0.56 & \multirow{5}{*}{0.68} \\
\hline & Hollister 03/24/1974 & 0.50 & & 0.56 & \\
\hline & Imperial Valley 5/19/1940 & 0.46 & & 0.89 & \\
\hline & Parkfield 06/28/1966 & 0.42 & & 0.72 & \\
\hline & San Fernando 02/09/1971 & 0.42 & & 0.67 & \\
\hline
\end{tabular}

TABLE 11: Plastic hinge rates of beams and columns in model KJ6.

\begin{tabular}{|c|c|c|c|c|c|}
\hline Specimen & Selected seismic waves & $P_{\mathrm{c}}$ & Average & $P_{\mathrm{b}}$ & Average \\
\hline \multirow{5}{*}{ KJ6 } & Northwest Calif. 02/09/1941 & 0.25 & \multirow{5}{*}{0.23} & 0.00 & \multirow{5}{*}{0.38} \\
\hline & Hollister $03 / 24 / 1974$ & 0.25 & & 0.11 & \\
\hline & Imperial Valley 5/19/1940 & 0.13 & & 0.67 & \\
\hline & Parkfield 06/28/1966 & 0.17 & & 0.28 & \\
\hline & San Fernando 02/09/1971 & 0.33 & & 0.83 & \\
\hline
\end{tabular}

TABLE 12: Maximum curvature ductility coefficients of beams and columns in model KJ1.

\begin{tabular}{|c|c|c|c|c|c|}
\hline Specimen & Selected seismic waves & $\mathrm{cd}_{\mathrm{c}}$ & Average & $\mathrm{cd}_{\mathrm{b}}$ & Average \\
\hline \multirow{5}{*}{ KJ1 } & Northwest Calif. 02/09/1941 & 1.06 & \multirow{5}{*}{1.18} & 1.11 & \multirow{5}{*}{1.18} \\
\hline & Hollister 03/24/1974 & 1.21 & & 1.15 & \\
\hline & Imperial Valley 5/19/1940 & 1.21 & & 1.20 & \\
\hline & Parkfield 06/28/1966 & 1.16 & & 1.21 & \\
\hline & San Fernando 02/09/1971 & 1.24 & & 1.23 & \\
\hline
\end{tabular}

Note: $\mathrm{cd}_{\mathrm{c}}$ is the maximum curvature ductility coefficient of columns and $\mathrm{cd}_{\mathrm{b}}$ is the maximum curvature ductility coefficient of beams. 
TABLE 13: Maximum curvature ductility coefficients of beams and columns in model KJ2.

\begin{tabular}{|c|c|c|c|c|c|}
\hline Specimen & Selected seismic waves & $\mathrm{cd}_{\mathrm{c}}$ & Average & $\mathrm{cd}_{\mathrm{b}}$ & Average \\
\hline \multirow{5}{*}{ KJ2 } & Northwest Calif. 02/09/1941 & 1.43 & \multirow{5}{*}{1.59} & 1.03 & \multirow{5}{*}{1.35} \\
\hline & Hollister 03/24/1974 & 1.63 & & 1.34 & \\
\hline & Imperial Valley $5 / 19 / 1940$ & 1.63 & & 1.56 & \\
\hline & Parkfield 06/28/1966 & 1.45 & & 1.14 & \\
\hline & San Fernando 02/09/1971 & 1.80 & & 1.67 & \\
\hline
\end{tabular}

TABLe 14: Maximum curvature ductility coefficients of beams and columns in model KJ3.

\begin{tabular}{|c|c|c|c|c|c|}
\hline Specimen & Selected seismic waves & $\mathrm{cd}_{\mathrm{c}}$ & Average & $\mathrm{cd}_{\mathrm{b}}$ & Average \\
\hline \multirow{5}{*}{$\mathrm{KJ} 3$} & Northwest Calif. 02/09/1941 & 1.43 & \multirow{5}{*}{1.63} & 1.17 & \multirow{5}{*}{1.52} \\
\hline & Hollister 03/24/1974 & 1.61 & & 1.46 & \\
\hline & Imperial Valley 5/19/1940 & 1.73 & & 1.75 & \\
\hline & Parkfield 06/28/1966 & 1.52 & & 1.41 & \\
\hline & San Fernando 02/09/1971 & 1.86 & & 1.81 & \\
\hline
\end{tabular}

TABLE 15: Maximum curvature ductility coefficients of beams and columns in model KJ4.

\begin{tabular}{|c|c|c|c|c|c|}
\hline Specimen & Selected seismic waves & $\mathrm{cd}_{\mathrm{c}}$ & Average & $\mathrm{cd}_{\mathrm{b}}$ & Average \\
\hline \multirow{5}{*}{ KJ4 } & Northwest Calif. 02/09/1941 & 1.70 & \multirow{5}{*}{2.19} & 1.34 & \multirow{5}{*}{2.08} \\
\hline & Hollister 03/24/1974 & 2.03 & & 2.04 & \\
\hline & Imperial Valley 5/19/1940 & 2.78 & & 2.98 & \\
\hline & Parkfield 06/28/1966 & 1.77 & & 1.79 & \\
\hline & San Fernando 02/09/1971 & 2.67 & & 2.24 & \\
\hline
\end{tabular}

TABLE 16: Maximum curvature ductility coefficients of beams and columns in model KJ5.

\begin{tabular}{|c|c|c|c|c|c|}
\hline Specimen & Selected seismic waves & $\mathrm{cd}_{\mathrm{c}}$ & Average & $\mathrm{cd}_{\mathrm{b}}$ & Average \\
\hline \multirow{5}{*}{ KJ5 } & Northwest Calif. 02/09/1941 & 1.65 & \multirow{5}{*}{1.95} & 1.13 & \multirow{5}{*}{1.53} \\
\hline & Hollister $03 / 24 / 1974$ & 1.97 & & 1.47 & \\
\hline & Imperial Valley 5/19/1940 & 2.07 & & 1.62 & \\
\hline & Parkfield 06/28/1966 & 1.71 & & 1.41 & \\
\hline & San Fernando 02/09/1971 & 2.33 & & 2.02 & \\
\hline
\end{tabular}

TABLE 17: Maximum curvature ductility coefficients of beams and columns in model KJ6.

\begin{tabular}{|c|c|c|c|c|c|}
\hline Specimen & Selected seismic waves & $\mathrm{cd}_{\mathrm{c}}$ & Average & $\mathrm{cd}_{\mathrm{b}}$ & Average \\
\hline \multirow{5}{*}{ KJ6 } & Northwest Calif. 02/09/1941 & 1.46 & \multirow{5}{*}{1.56} & 0.98 & \multirow{5}{*}{1.73} \\
\hline & Hollister $03 / 24 / 1974$ & 1.50 & & 1.17 & \\
\hline & Imperial Valley 5/19/1940 & 1.70 & & 2.50 & \\
\hline & Parkfield 06/28/1966 & 1.17 & & 1.27 & \\
\hline & San Fernando 02/09/1971 & 1.97 & & 2.72 & \\
\hline
\end{tabular}

corresponding to the seismic fortification intensity. For model KJ6 with 9-degree $(0.40 \mathrm{~g})$ seismic intensity, the plastic hinge rates of the beams and columns exhibited a descending trend, which indicates that the structural stability could be better guaranteed if the amplification coefficient and 1.2 $\Sigma M_{\text {bua }}$ are adjusted according to seismic code.

4.2.2. Curvature Ductility Coefficients of Beams and Columns. The curvature ductility coefficients of the beams and columns are defined as the ratios of maximum curvature to yield curvature, which reflect the plastic rotation of members. The curvature ductility coefficients of the beams and columns in KJ1-KJ6 are shown in Tables 12-17.
It can be seen from the tables that there was not a significant difference between the curvature ductility coefficients of the beams and columns with different seismic fortification intensities. This indicates that excessive plastic deformation may have occurred in the columns prior to the beams and thus led to the degradation of structural ductility due to the sharp loss of vertical carrying capacity.

The curvature ductility coefficients of the beams and columns of KJ1 were small, owing to the low seismic intensity and slight damage. For KJ6 with 9-degree $(0.40 \mathrm{~g})$ seismic intensity, the curvature ductility coefficient of the columns decreased while that of the beams increased slightly, which indicates that the beam-hinge mechanism could be achieved while meeting the adjustment of the amplification coefficient and $1.2 \Sigma M_{\text {bua. }}$ 
TABLE 18: Design parameters of numerical examples (considering the limit values in Table 2).

\begin{tabular}{|c|c|c|c|c|c|c|c|}
\hline \multirow{2}{*}{ Frame } & \multirow{2}{*}{ Component type } & \multirow{2}{*}{ Sectional size } & \multirow{2}{*}{ Floor } & \multicolumn{2}{|c|}{ Reinforcement details } & \multirow{2}{*}{$k$} & \multirow{2}{*}{ Amplification factors } \\
\hline & & & & Interior & Exterior & & \\
\hline \multirow{3}{*}{ KJ7 } & Reams & $250 \times 500$ & $1-5$ & $4 \phi 14(2 \$ 18)$ & $4 \$ 14(2 \$ 18)$ & & \\
\hline & Beams & $250 \times 500$ & 6 & $3 \Phi 14(2 \Phi 18)$ & $3 \phi 14(2 \Phi 18)$ & 0.395 & 5.661 \\
\hline & Columns & $550 \times 550$ & $1-6$ & \multicolumn{2}{|c|}{$4 \Phi 16+8 \Phi 14$} & & \\
\hline \multirow{4}{*}{ KJ8 } & \multirow{3}{*}{ Beams } & \multirow{3}{*}{$300 \times 600$} & $1-4$ & $2 \Phi 16+2 \Phi 14(3 \phi 14)$ & $4 \phi 16(3 \phi 14)$ & & \\
\hline & & & 5 & \multirow{2}{*}{\multicolumn{2}{|c|}{$4 \Phi 14(3 \Phi 14)$}} & & \\
\hline & & & 6 & $3 \phi 14(3 \phi 14)$ & & $0.55 /$ & 5.344 \\
\hline & Columns & $600 \times 600$ & $1-6$ & & & & \\
\hline \multirow{4}{*}{ KJ9 } & & & $1-4$ & $2 \phi 18+2 \Phi 16(2 \phi 18)$ & $2 \Phi 18+2 \Phi 16(2 \phi 18)$ & & \\
\hline & Beams & $250 \times 550$ & 5 & $3 \$ 16(2 \phi 18)$ & $2 \phi 16+2 \Phi 14(2 \phi 18)$ & 0.531 & 713 \\
\hline & & & 6 & $4 \Phi 14(2 \Phi 16)$ & $3 \phi 14(2 \Phi 16)$ & 0.501 & 4.715 \\
\hline & Columns & $550 \times 550$ & $1-6$ & \multicolumn{2}{|c|}{$12 \$ 16$} & & \\
\hline \multirow{5}{*}{ KJ10 } & \multirow{3}{*}{ Beams } & \multirow{3}{*}{$250 \times 600$} & $1-4$ & $2 \Phi 20+2 \Phi 16(2 \phi 18)$ & $2 \phi 20+2 \phi 18(2 \phi 20)$ & \multirow{5}{*}{0.709} & \multirow{5}{*}{3.836} \\
\hline & & & 5 & $2 \Phi 16+2 \Phi 14(2 \Phi 18)$ & $2 \phi 16+2 \Phi 14(2 \phi 18)$ & & \\
\hline & & & 6 & & $\$ 18)$ & & \\
\hline & \multirow{2}{*}{ Columns } & \multirow{2}{*}{$550 \times 550$} & 1 & \multirow{2}{*}{\multicolumn{2}{|c|}{$\begin{array}{c}4 \Phi 20+4 \Phi 20+4 \Phi 18 \\
4 \Phi 18+8 \Phi 16\end{array}$}} & & \\
\hline & & & $2-6$ & & & & \\
\hline \multirow{8}{*}{ KJ11 } & \multirow{3}{*}{ Beams } & \multirow{3}{*}{$300 \times 600$} & $1-4$ & $4 \Phi 25(4 \Phi 20)$ & $25+2 \Phi 20(2 \Phi 22+2 \Phi 20)$ & \multirow{8}{*}{0.601} & \multirow{8}{*}{2.975} \\
\hline & & & 5 & $2 \phi 20+2 \phi 18(4 \phi 16)$ & $2 \phi 20+2 \phi 18(4 \phi 16)$ & & \\
\hline & & & 6 & & $\$ 16)$ & & \\
\hline & & & 1 & $16 \$ 25$ & $20 \$ 25$ & & \\
\hline & & & 2 & $4 \Phi 22+4 \Phi 22+4 \Phi 20$ & $4 \Phi 25+4 \Phi 20+4 \Phi 25$ & & \\
\hline & Columns & $600 \times 600$ & 3 & $4 \Phi 22+4 \Phi 20+4 \Phi 18$ & $4 \Phi 25+4 \Phi 20+4 \Phi 22$ & & \\
\hline & & & 4 & $4 \phi 22+4 \Phi 20+4 \Phi 18$ & $12 \Phi 22$ & & \\
\hline & & & $5-6$ & $12 \Phi 22$ & $12 \Phi 22$ & & \\
\hline & & & $1-4$ & $4 \Phi 25(2 \Phi 22+2 \Phi 20)$ & $2 \Phi 25+2 \Phi 20(4 \Phi 22)$ & & \\
\hline & Beams & $300 \times 650$ & 5 & $2 \Phi 20+2 \Phi 18(4 \Phi 16)$ & $2 \phi 20+2 \Phi 18(4 \Phi 16)$ & & \\
\hline & & & 6 & & $\$ 16)$ & & \\
\hline KJ12 & & & 1 & $24 \Phi 25$ & $20 \$ 28$ & 0730 & 2733 \\
\hline & & & 2 & $4 \phi 25+6 \Phi 25+6 \Phi 20$ & $4 \phi 25+4 \phi 20+8 \Phi 25$ & 0.730 & 2.133 \\
\hline & Columns & $600 \times 600$ & 3 & $14 \$ 25$ & $4 \Phi 25+4 \Phi 20+6 \Phi 25$ & & \\
\hline & & & 4 & $14 \$ 25$ & $12 \Phi 22$ & & \\
\hline & & & $5-6$ & & & & \\
\hline
\end{tabular}

TABle 19: Plastic hinge rates of beams and columns in model KJ7.

\begin{tabular}{|c|c|c|c|c|c|}
\hline Specimen & Selected seismic waves & $P_{\mathrm{c}}$ & Average & $P_{\mathrm{b}}$ & Average \\
\hline \multirow{5}{*}{ KJ7 } & Northwest Calif. 02/09/1941 & 0.08 & \multirow{5}{*}{0.12} & 0.17 & \multirow{5}{*}{0.33} \\
\hline & Hollister 03/24/1974 & 0.08 & & 0.28 & \\
\hline & Imperial Valley 5/19/1940 & 0.13 & & 0.39 & \\
\hline & Parkfield 06/28/1966 & 0.13 & & 0.39 & \\
\hline & San Fernando 02/09/1971 & 0.17 & & 0.44 & \\
\hline
\end{tabular}

TABle 20: Plastic hinge rates of beams and columns in model KJ8.

\begin{tabular}{lcccc}
\hline Specimen & Selected seismic waves & $P_{\mathrm{c}}$ & Average & $P_{\mathrm{b}}$ \\
\hline & Northwest Calif. 02/09/1941 & 0.08 & 0.33 & Average \\
KJ8 & Hollister 03/24/1974 & 0.17 & 0.50 & 0.56 \\
& Imperial Valley 5/19/1940 & 0.17 & 0.18 & 0.50 \\
& Parkfield 06/28/1966 & 0.25 & & 0.67 \\
\hline
\end{tabular}

TABLE 21: Plastic hinge rates of beams and columns in model KJ9.

\begin{tabular}{|c|c|c|c|c|c|}
\hline Specimen & Selected seismic waves & $P_{\mathrm{c}}$ & Average & $P_{\mathrm{b}}$ & Average \\
\hline \multirow{5}{*}{ KJ9 } & Northwest Calif. 02/09/1941 & 0.17 & \multirow{5}{*}{0.26} & 0.50 & \multirow{5}{*}{0.62} \\
\hline & Hollister $03 / 24 / 1974$ & 0.21 & & 0.67 & \\
\hline & Imperial Valley 5/19/1940 & 0.29 & & 0.61 & \\
\hline & Parkfield 06/28/1966 & 0.33 & & 0.67 & \\
\hline & San Fernando 02/09/1971 & 0.29 & & 0.67 & \\
\hline
\end{tabular}


TABLE 22: Plastic hinge rates of beams and columns in model KJ10.

\begin{tabular}{|c|c|c|c|c|c|}
\hline Specimen & Selected seismic waves & $P_{\mathrm{c}}$ & Average & $P_{\mathrm{b}}$ & Average \\
\hline \multirow{5}{*}{ KJ10 } & Northwest Calif. 02/09/1941 & 0.17 & \multirow{5}{*}{0.29} & 0.50 & \multirow{5}{*}{0.67} \\
\hline & Hollister 03/24/1974 & 0.25 & & 0.67 & \\
\hline & Imperial Valley 5/19/1940 & 0.38 & & 0.61 & \\
\hline & Parkfield 06/28/1966 & 0.33 & & 0.67 & \\
\hline & San Fernando 02/09/1971 & 0.33 & & 0.89 & \\
\hline
\end{tabular}

TABLE 23: Plastic hinge rates of beams and columns in model KJ11.

\begin{tabular}{|c|c|c|c|c|c|}
\hline Specimen & Selected seismic waves & $P_{c}$ & Average & $P_{\mathrm{b}}$ & Average \\
\hline \multirow{5}{*}{ KJ11 } & Northwest Calif. 02/09/1941 & 0.33 & \multirow{5}{*}{0.34} & 0.56 & \multirow{5}{*}{0.73} \\
\hline & Hollister 03/24/1974 & 0.42 & & 0.72 & \\
\hline & Imperial Valley 5/19/1940 & 0.33 & & 0.83 & \\
\hline & Parkfield 06/28/1966 & 0.38 & & 0.67 & \\
\hline & San Fernando 02/09/1971 & 0.25 & & 0.89 & \\
\hline
\end{tabular}

TABLE 24: Plastic hinge rates of beams and columns in model KJ12.

\begin{tabular}{|c|c|c|c|c|c|}
\hline Specimen & Selected seismic waves & $P_{\mathrm{c}}$ & Average & $P_{\mathrm{b}}$ & Average \\
\hline \multirow{5}{*}{ KJ12 } & Northwest Calif. 02/09/1941 & 0.17 & \multirow{5}{*}{0.18} & 0.22 & \multirow[t]{5}{*}{0.38} \\
\hline & Hollister 03/24/1974 & 0.13 & & 0.17 & \\
\hline & Imperial Valley 5/19/1940 & 0.17 & & 0.44 & \\
\hline & Parkfield 06/28/1966 & 0.25 & & 0.28 & \\
\hline & San Fernando 02/09/1971 & 0.17 & & 0.94 & \\
\hline
\end{tabular}

TABle 25: Maximum curvature ductility coefficients of beams and columns in model KJ7.

\begin{tabular}{|c|c|c|c|c|c|}
\hline Specimen & Selected seismic waves & $\mathrm{cd}_{\mathrm{c}}$ & Average & $\mathrm{cd}_{\mathrm{b}}$ & Average \\
\hline \multirow{5}{*}{ KJ7 } & Northwest Calif. 02/09/1941 & 1.15 & \multirow{5}{*}{1.11} & 1.08 & \multirow{5}{*}{1.23} \\
\hline & Hollister 03/24/1974 & 1.03 & & 1.19 & \\
\hline & Imperial Valley 5/19/1940 & 1.09 & & 1.30 & \\
\hline & Parkfield 06/28/1966 & 1.14 & & 1.17 & \\
\hline & San Fernando 02/09/1971 & 1.16 & & 1.41 & \\
\hline
\end{tabular}

TABLE 26: Maximum curvature ductility coefficients of beams and columns in model KJ8.

\begin{tabular}{|c|c|c|c|c|c|}
\hline Specimen & Selected seismic waves & $\mathrm{cd}_{\mathrm{c}}$ & Average & $\mathrm{cd}_{\mathrm{b}}$ & Average \\
\hline \multirow{5}{*}{ KJ8 } & Northwest Calif. 02/09/1941 & 1.54 & \multirow{5}{*}{1.49} & 1.48 & \multirow{5}{*}{1.62} \\
\hline & Hollister $03 / 24 / 1974$ & 1.28 & & 1.39 & \\
\hline & Imperial Valley 5/19/1940 & 1.33 & & 1.54 & \\
\hline & Parkfield 06/28/1966 & 1.58 & & 1.76 & \\
\hline & San Fernando 02/09/1971 & 1.73 & & 1.92 & \\
\hline
\end{tabular}

TABLE 27: Maximum curvature ductility coefficients of beams and columns in model KJ9.

\begin{tabular}{|c|c|c|c|c|c|}
\hline Specimen & Selected seismic waves & $\mathrm{cd}_{\mathrm{c}}$ & Average & $\mathrm{cd}_{\mathrm{b}}$ & Average \\
\hline \multirow{5}{*}{ KJ9 } & Northwest Calif. 02/09/1941 & 1.34 & \multirow{5}{*}{1.50} & 1.97 & \multirow{5}{*}{1.90} \\
\hline & Hollister $03 / 24 / 1974$ & 1.51 & & 1.29 & \\
\hline & Imperial Valley 5/19/1940 & 1.56 & & 1.78 & \\
\hline & Parkfield 06/28/1966 & 1.48 & & 2.13 & \\
\hline & San Fernando 02/09/1971 & 1.63 & & 2.34 & \\
\hline
\end{tabular}

TABLE 28: Maximum curvature ductility coefficients of beams and columns in model KJ10.

\begin{tabular}{|c|c|c|c|c|c|}
\hline Specimen & Selected seismic waves & $\mathrm{cd}_{\mathrm{c}}$ & Average & $\mathrm{cd}_{\mathrm{b}}$ & Average \\
\hline \multirow{5}{*}{ KJ10 } & Northwest Calif. 02/09/1941 & 1.69 & \multirow{5}{*}{1.99} & 2.20 & \multirow{5}{*}{2.17} \\
\hline & Hollister 03/24/1974 & 2.06 & & 1.79 & \\
\hline & Imperial Valley 5/19/1940 & 2.21 & & 1.88 & \\
\hline & Parkfield 06/28/1966 & 1.64 & & 2.32 & \\
\hline & San Fernando 02/09/1971 & 2.34 & & 2.64 & \\
\hline
\end{tabular}


TABLE 29: Maximum curvature ductility coefficients of beams and columns in model KJ11.

\begin{tabular}{|c|c|c|c|c|c|}
\hline Specimen & Selected seismic waves & $\mathrm{cd}_{\mathrm{c}}$ & Average & $\mathrm{cd}_{\mathrm{b}}$ & Average \\
\hline \multirow{5}{*}{ KJ11 } & Northwest Calif. 02/09/1941 & 1.57 & \multirow{5}{*}{1.69} & 1.89 & \multirow{5}{*}{2.13} \\
\hline & Hollister $03 / 24 / 1974$ & 1.85 & & 2.04 & \\
\hline & Imperial Valley 5/19/1940 & 1.43 & & 1.35 & \\
\hline & Parkfield 06/28/1966 & 1.71 & & 2.19 & \\
\hline & San Fernando 02/09/1971 & 1.87 & & 3.16 & \\
\hline
\end{tabular}

TABLE 30: Maximum curvature ductility coefficients of beams and columns in model KJ12.

\begin{tabular}{|c|c|c|c|c|c|}
\hline Specimen & Selected seismic waves & $\mathrm{cd}_{\mathrm{c}}$ & Average & $\mathrm{cd}_{\mathrm{b}}$ & Average \\
\hline \multirow{5}{*}{ KJ12 } & Northwest Calif. 02/09/1941 & 1.14 & \multirow{5}{*}{1.32} & 1.95 & \multirow{5}{*}{2.03} \\
\hline & Hollister 03/24/1974 & 1.66 & & 1.29 & \\
\hline & Imperial Valley 5/19/1940 & 1.01 & & 2.33 & \\
\hline & Parkfield 06/28/1966 & 1.23 & & 1.34 & \\
\hline & San Fernando 02/09/1971 & 1.58 & & 3.22 & \\
\hline
\end{tabular}

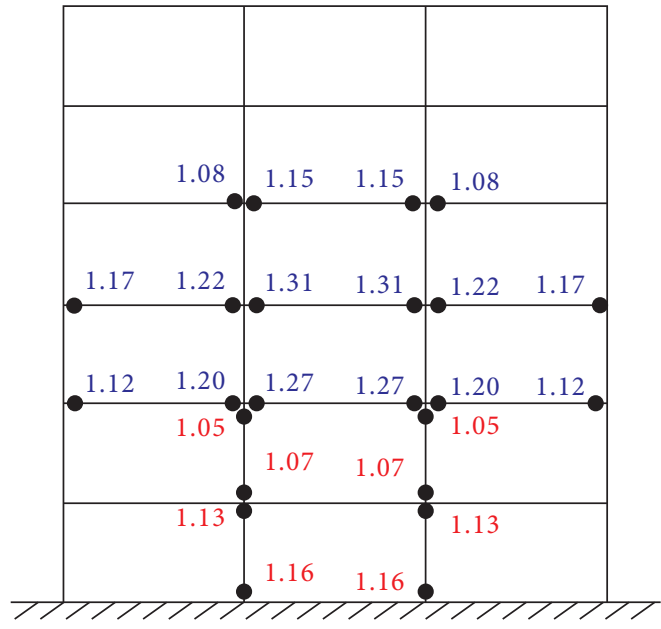

(a)

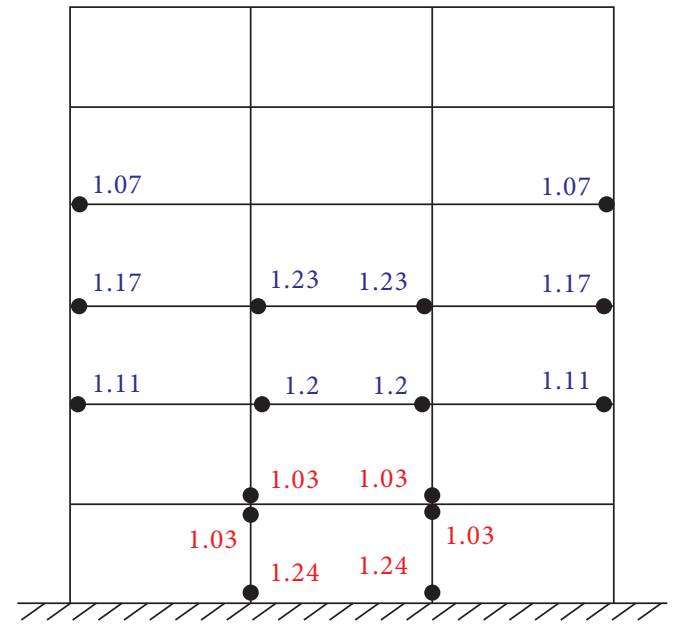

(b)

Figure 17: Plastic hinge distribution with 6-degree ( $0.05 \mathrm{~g})$ fortification intensity. (a) Considering the beam-to-column linear stiffness ratio limit values. (b) Not considering the beam-to-column linear stiffness ratio limit values.

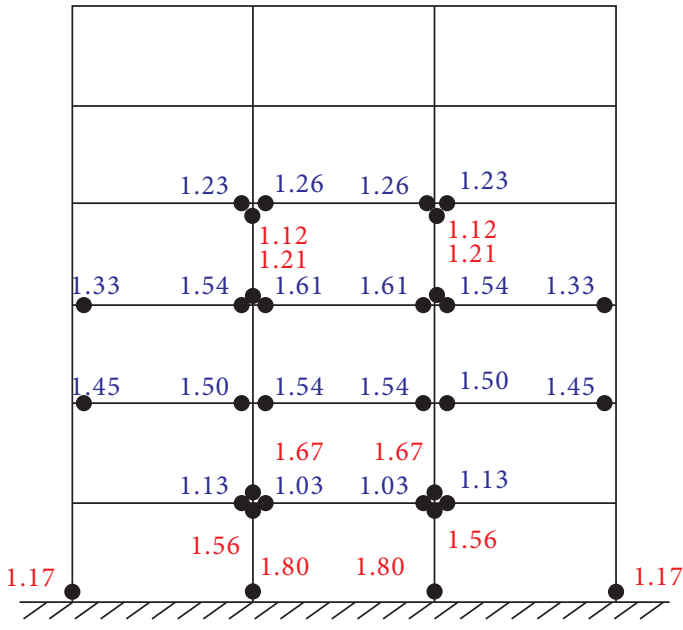

(a)

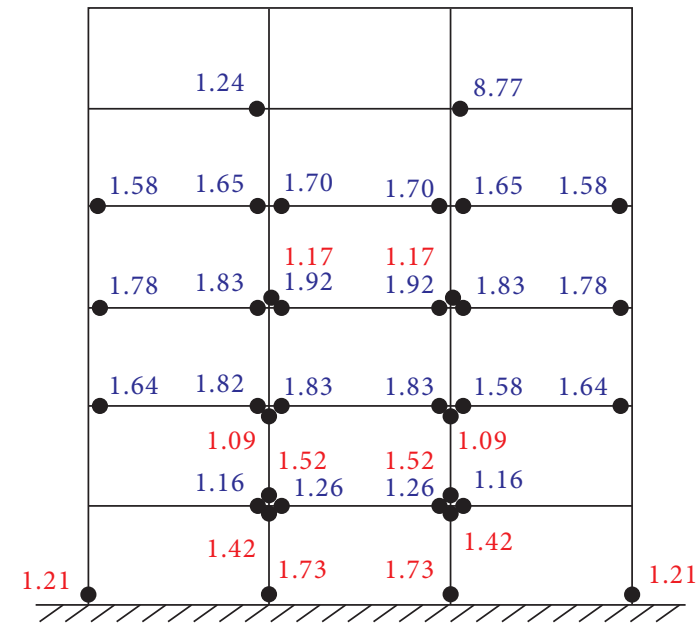

(b)

FIgURE 18: Plastic hinge distribution with 7-degree $(0.10 \mathrm{~g})$ fortification intensity. (a) Considering the beam-to-column linear stiffness ratio limit values. (b) Not considering the beam-to-column linear stiffness ratio limit values. 


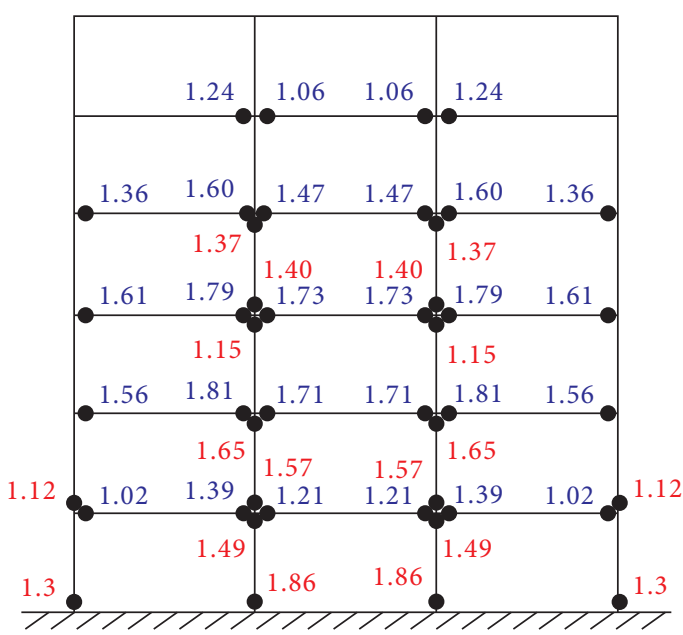

(a)

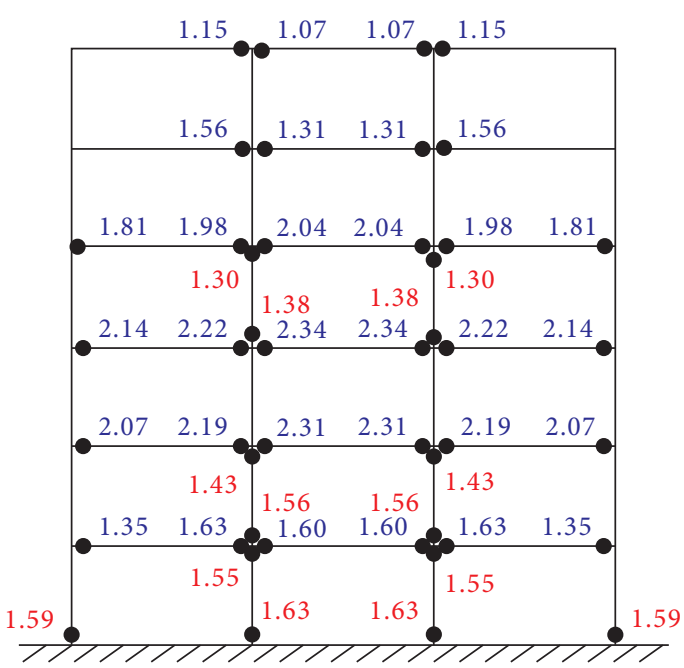

(b)

FIGURE 19: Plastic hinge distribution with 7-degree $(0.15 \mathrm{~g})$ fortification intensity. (a) Considering the beam-to-column linear stiffness ratio limit values. (b) Not considering the beam-to-column linear stiffness ratio limit values.

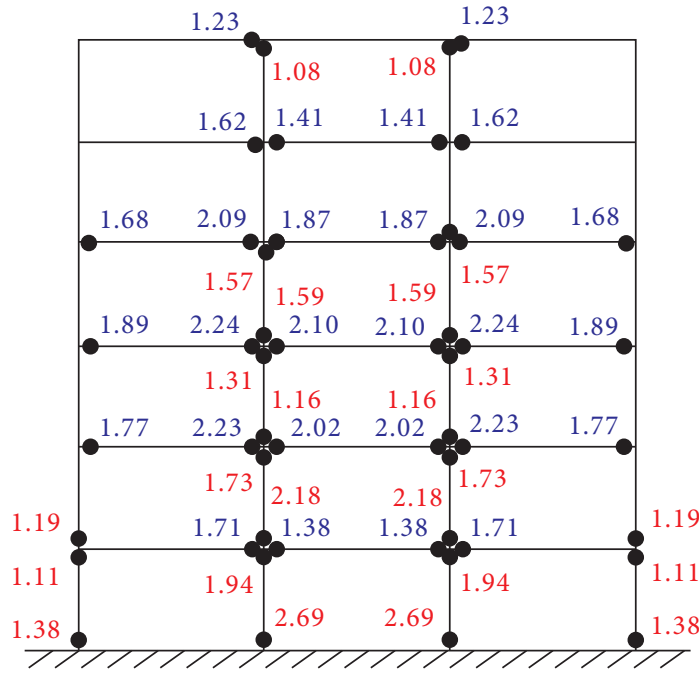

(a)

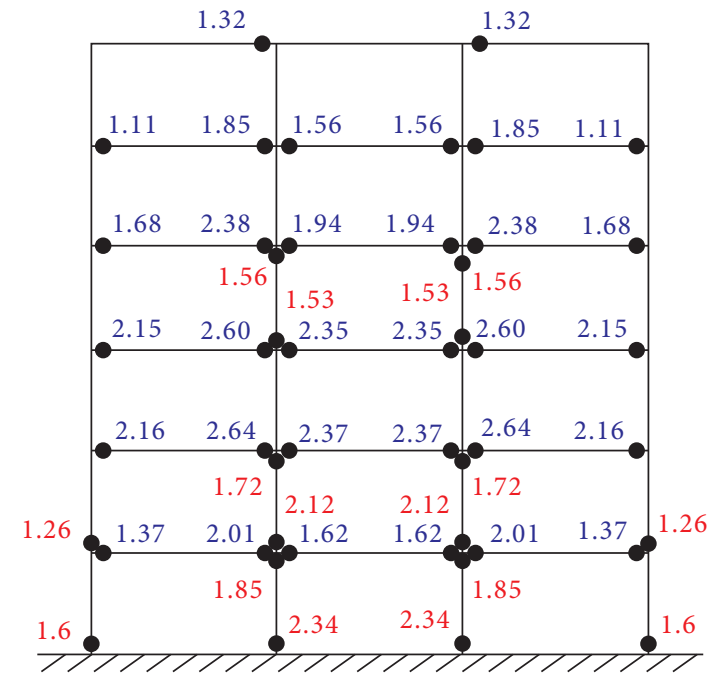

(b)

Figure 20: Plastic hinge distribution with 8-degree (0.20 g) fortification intensity. (a) Considering the beam-to-column linear stiffness ratio limit values. (b) Not considering the beam-to-column linear stiffness ratio limit values.

4.3. Structural Failure Modes considering Limit Values. The sectional sizes of the beams and columns were adjusted to reduce the beam-to-column linear stiffness ratios below the limit values presented in Table 2 . The adjusted numerical models of 6 -degree $(0.05 \mathrm{~g})$, 7 -degree $(0.10 \mathrm{~g}), 7$-degree $(0.15 \mathrm{~g}), 8$-degree $(0.20 \mathrm{~g}), 8$-degree $(0.30 \mathrm{~g})$, and 9 -degree $(0.40 \mathrm{~g})$ seismic intensity were denoted by KJ7, KJ8, KJ9, KJ10, KJ11, and KJ12, respectively. The sectional sizes and reinforcement details are shown in Table 18.

4.3.1. Plastic Hinge Rates of Beams and Columns. The plastic hinge rates of the beams and columns in KJ7-KJ12 are shown in Tables 19-24.
It can be seen from the tables above that the plastic hinge rates of the beams were significantly larger than those of the columns with the consideration of the limit values.

The failure mode presents as the desired beam-hinge mechanism, which indicates that controlling the structural beam-to-column linear stiffness ratio within reasonable limit values during the design phase is beneficial in postponing the formation of plastic hinges in the columns and preventing structural collapse due to inadequate vertical carrying capacity.

4.3.2. Curvature Ductility Coefficients of Beams and Columns. The curvature ductility coefficients of the beams and columns in KJ7-KJ12 are shown in Tables 25-30. 


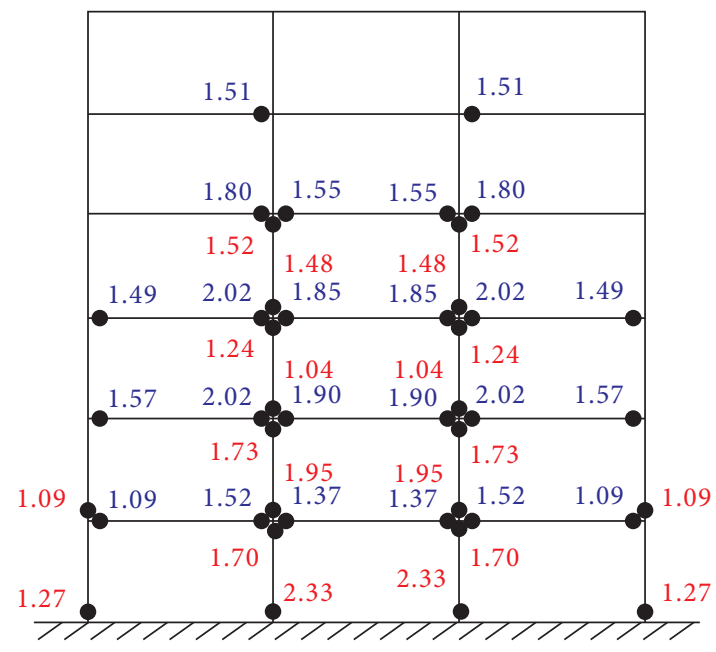

(a)

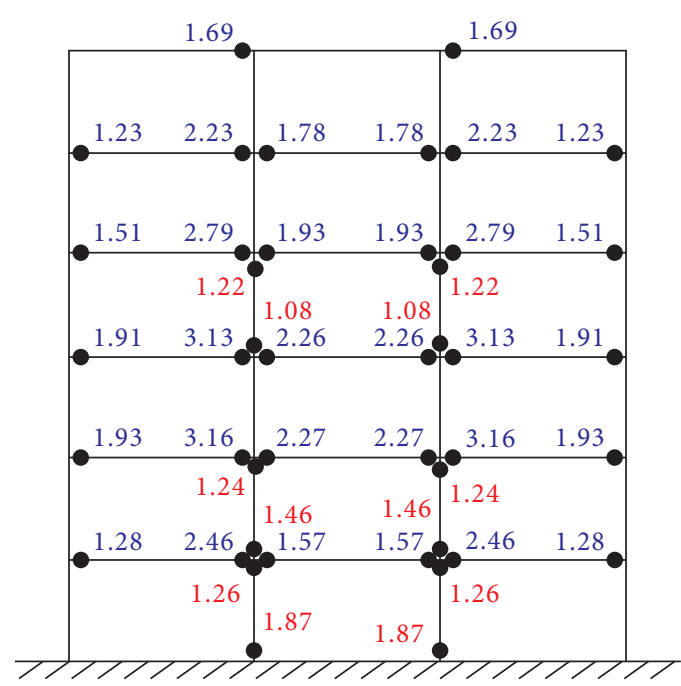

(b)

FIgURE 21: Plastic hinge distribution with 8-degree $(0.30 \mathrm{~g})$ fortification intensity. (a) Considering the beam-to-column linear stiffness ratio limit values. (b) Not considering the beam-to-column linear stiffness ratio limit values.

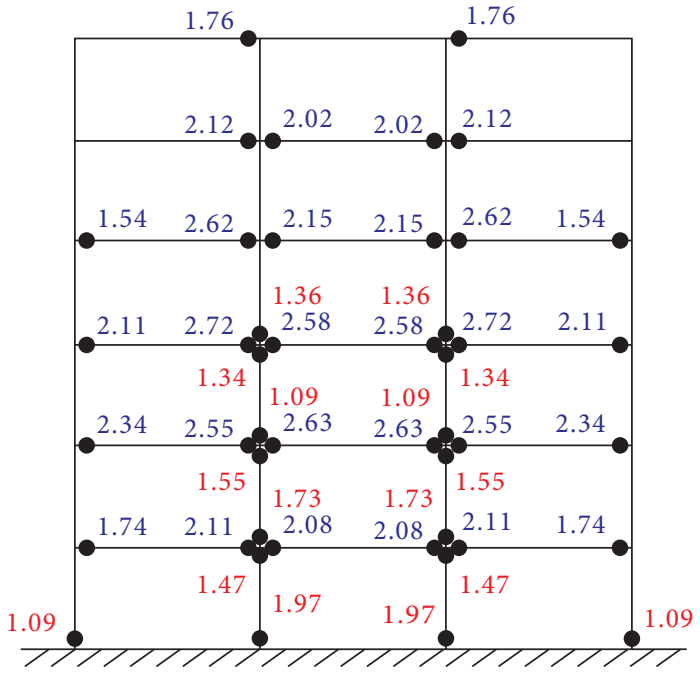

(a)

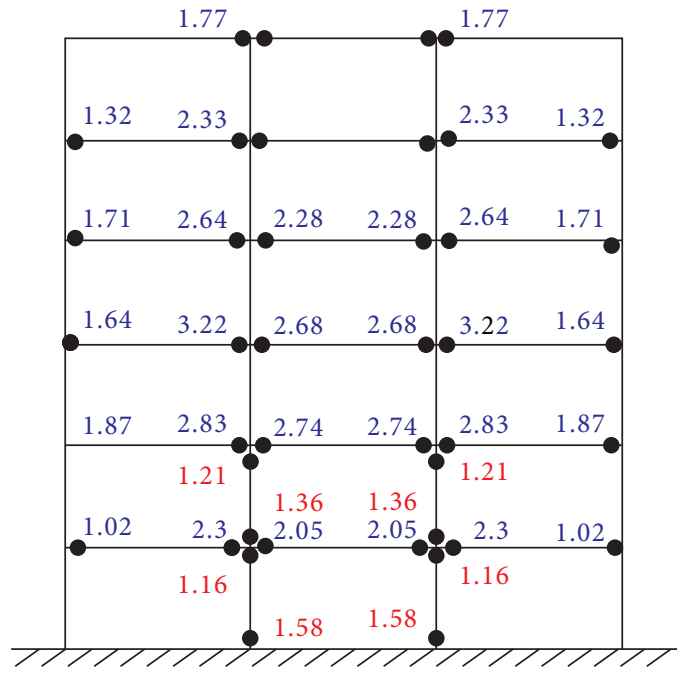

(b)

Figure 22: Plastic hinge distribution with 8-degree $(0.40 \mathrm{~g})$ fortification intensity. (a) Considering the beam-to-column linear stiffness ratio limit values. (b) Not considering the beam-to-column linear stiffness ratio limit values.

It can be seen from the tables above that the plastic deformation of the beams increases significantly while that of the columns remains almost unchanged. This indicates that a suitable adjustment of the relationship between beam and column stiffness could decrease the plastic deformation of the columns and thereby produce the beam-hinge mechanism effectively.

4.4. Distribution of Plastic Hinges. The worst-case scenario occurs when the plastic hinge rates and curvature ductility coefficients reach their maximum values simultaneously. This is represented by the ground motion named San Fernando in models KJ1-KJ12. A comparison of the plastic hinge distributions with and without consideration of the beam-to- column linear stiffness ratio limit values is shown in Figures 17-22 (the numbers in the figures are the curvature ductility coefficients of members). As shown in the figures above, both the formation of plastic hinges and the curvature ductility coefficients in the columns decreased while those in the beams increased significantly when the beam-to-column linear stiffness ratio was taken into consideration.

The plastic hinges in the columns gradually transferred to the beams and the structural failure modes were dominated by beam hinges.

\section{Conclusion and Discussion}

The influence of the beam-to-column linear stiffness ratio on the failure modes of $\mathrm{RC}$ frame structures was investigated in 
detail. Various limit values of beam-to-column linear stiffness ratio for different aseismic grades were proposed and verified by the experimental results of RC frames under low reversed cyclic loading. Nonlinear dynamic analyses were performed on plane frame models designed nonconforming and conforming to the limit values. The conclusions reached are all based on the frames used in this study and shown as follows:

(1) The material strength, section size, reinforcement ratio, and axial compression ratio were the most sensitive factors influencing the structural yielding mechanism. The relative linear stiffness of beams to columns had a significant effect on the failure mechanism of an RC moment-resisting frame. The beam-hinge mechanism was easily achieved if the actual beam-to-column linear stiffness ratio was less than the recommended limit values.

(2) Experimental results showed that the beam-to-column linear stiffness ratio made a difference to the relative damage of structural components. In buildings with larger beam-to-column linear stiffness ratios, plastic hinges are more concentrated in the columns and develop slower in the beams. In buildings with lower beam-to-column linear stiffness ratios, the beam-to-column damage ratios were larger, which indicates that the damage degree of the beams was more serious than that of the columns. This is beneficial for facilitating a beam-hinge mechanism.

(3) Dynamic analysis results demonstrated that the relative flexural strengths of beams to columns-as specified in many design codes - may not be adequate to guarantee SCWB seismic behavior. That is, the relative stiffness of beams to columns should also be considered in the structural design. Buildings conforming to the beamto-column linear stiffness ratio limit values exhibited an apparent reduction of plastic hinge formation and plastic deformation in the columns.

Existing research indicates that cast-in-situ slabs enhance the moment resistance and stiffness of beams, so the effective slab width should be considered when calculating the beam-tocolumn linear stiffness ratio limit values. However, this topic may require further subject investigation. The presented governing equation of the yielding mechanism is based on the assumptions that the yielding of longitudinal reinforcements is equal to that of member sections, and the limit values and conclusions were limited to elastic theory; thus, all the values and conclusions should be extended to the elastoplastic stage. The nonlinear dynamic analyses were conducted with the limitations of selected seismic records and a simplified numerical model. In-depth studies based on spatial numerical models and larger quantities of seismic records are recommended to investigate the distribution of plastic hinges.

\section{Data Availability}

The data in Figures 11 and 12 used to support the findings of this study were related to the original data of experiments funded by the National Natural Science Foundation of China and so cannot be made freely available concerning legal restrictions. Requests for access to these data should be made to the leader of this academic project (e-mail addresses: bqliu@ chd.edu.cn). The data in Tables 6-30 and Figures 17-22 used to support the findings of this study were computed by commercial software Abaqus. The other data used to support the findings of this study were obtained through equations presented in the article, and the calculation methods were included within the paper.

\section{Conflicts of Interest}

The authors declare that there are no conflicts of interest.

\section{Authors' Contributions}

J. S., B. L., and Y. M were involved in design and implementation. All authors contributed to analysis and testing. All authors contributed to editing and reviewing the manuscript.

\section{Acknowledgments}

This research was partially supported by the National Natural Science Foundation of China (Grant no. 51578077) and the International Science and Technology Cooperation Project of Shaanxi Province (Grant no. 2016KW-056).

\section{References}

[1] A. Bayraktar, A. C. Altunişik, and M. Pehlivan, "Performance and damages of reinforced concrete buildings during the October 23 and November 9, 2011 Van, Turkey, earthquakes," Soil Dynamics and Earthquake Engineering, vol. 53, pp. 49-72, 2013.

[2] American Concrete Institute, ACI318-14 Building Code Requirements for Structural Concrete, American Concrete Institute, Farmington Hill, MI, USA, 2014.

[3] British Standard, Euro Code 8. Design of Structures for Earthquake Resistance-Part 1: General Rules, Seismic Actions and Rules for Buildings, British Standard, London, UK, 2004.

[4] China Architecture and Building Press, GB50011-2010 Code for Seismic Design of Buildings, China Architecture and Building Press, Beijing, China, 2010.

[5] Ministry of Public Works and Settlement, TEC-2007 Regulations on Structures Constructed in Disaster Regions, Ministry of Public Works and Settlement, Ankara, Turkey, 2007.

[6] Standards New Zealand, NZS3101 Concrete Structures Standard, Standards New Zealand, Wellington, New Zealand, 2006.

[7] M. Nakashima and S. Sawaizumi, "Column-to-beam strength ratio required for ensuring beam-collapse mechanisms in earthquake responses of steel moment frames," in Proceedings of the 12th World Conference on Earthquake Engineering, vol. 38, pp. 52-29, Auckland, New Zealand, January 2000.

[8] K. L. Dooley and J. M. Bracci, "Seismic evaluation of columnto-beam strength ratios in reinforced concrete frames," $A C I$ Structural Journal, vol. 98, no. 6, pp. 834-851, 2001.

[9] G. L. Kuntz and J. Browning, "Reduction of column yielding during earthquakes for reinforced concrete frames," ACI Structural Journal, vol. 100, no. 5, pp. 573-580, 2003. 
[10] R. A. Medina and H. Krawinkler, "Strength demand issues relevant for the seismic design of moment-resisting frames," Earthquake Spectra, vol. 21, no. 2, pp. 415-439, 2005.

[11] L. F. Ibarra and H. Krawinkler, "Global collapse of frame structures under seismic excitations," Stanford University, San Francisco, CA, USA, Dissertation, 2005.

[12] C. B. Haselton, A. B. Liel, G. G. Deierlein, B. S. Dean, and J. H. Chou, "Seismic collapse safety of reinforced concrete buildings. I: assessment of ductile moment frames," Journal of Structural Engineering, vol. 137, no. 4, pp. 481-491, 2011.

[13] Z. Chang, G. Xing, D. Luo, and B. Liu, "Seismic behavior and strength prediction of corroded RC columns subjected to cyclic loading," Magazine of Concrete Research, pp. 1-53, 2019.

[14] K. Sze-Wei, K. Saravanan, and T. Ching-Seong, "A review of surface deformation and strain measurement using two-dimensional digital image correlation," Metrology and Measurement Systems, vol. 23, no. 3, pp. 461-480, 2016.

[15] J. Blaber, B. Adair, and A. Antoniou, "Ncorr: open-source 2D digital image correlation Matlab software," Experimental Mechanics, vol. 55, no. 6, pp. 1105-1122, 2015.

[16] S. S. F. Mehanny and G. G. Deierlein, "Seismic damage and collapse assessment of composite moment frames," Journal of Structural Engineering, vol. 127, no. 9, pp. 1045-1053, 2001.

[17] B. Wang, H. J. Dai, Y. T. Bai, and K. Xiao, "Influence mechanism of steel diagonal braces on mechanical behavior of steel truss-RC tubular column hybrid structure," Journal of Earthquake Engineering, pp. 1-27, 2019.

[18] Z. Qu and L. P. Ye, "Strength deterioration model based on effective hysteretic energy dissipation for RC members under cyclic loading," Engineering Mechanics, vol. 28, pp. 45-51, 2011.

[19] D. C. Kent and R. Park, "Flexural members with confined concrete," Journal of the Structural (ASCE), vol. 97, pp. 1969-1990, 1971.

[20] B. D. Scott, R. Park, and M. J. N. Priestley, "Stress-strain behavior of concrete confined by overlapping hoops at low and high strain rates," ACI Journal Proceedings, vol. 79, no. 1, pp. 13-27, 1982.

[21] R. W. Clough, "Effect of stiffness degradation on earthquake ductility requirements," University of California, Berkeley, CA, USA, Dissertation, 1966.

[22] E. I. Katsanos, A. G. Sextos, and G. D. Manolis, "Selection of earthquake ground motion records: a state-of-the-art review from a structural engineering perspective," Soil Dynamics and Earthquake Engineering, vol. 30, no. 4, pp. 157-169, 2010. 


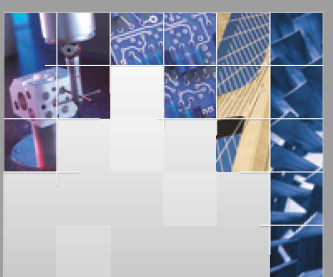

\section{Enfincering}
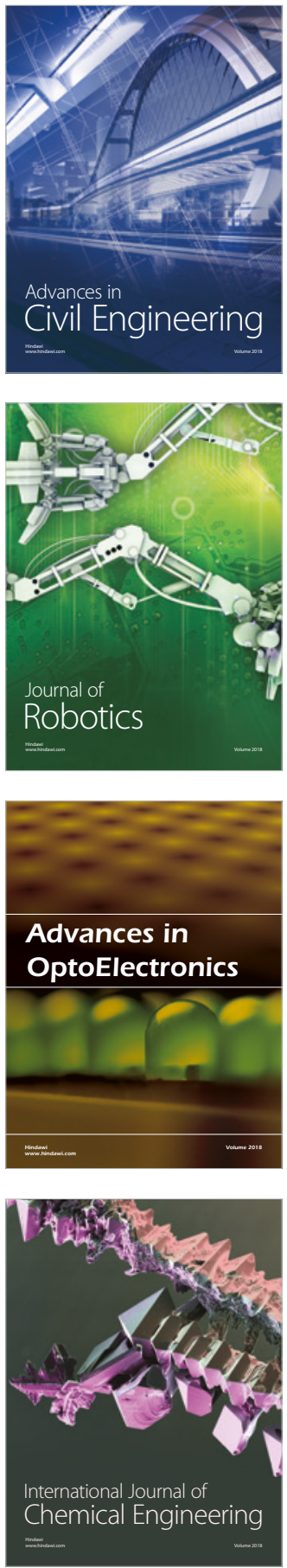

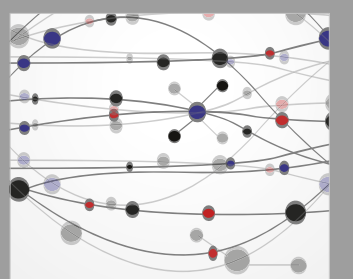

\section{Rotating \\ Machinery}

The Scientific World Journal

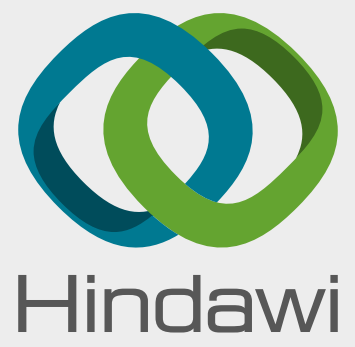

Submit your manuscripts at

www.hindawi.com
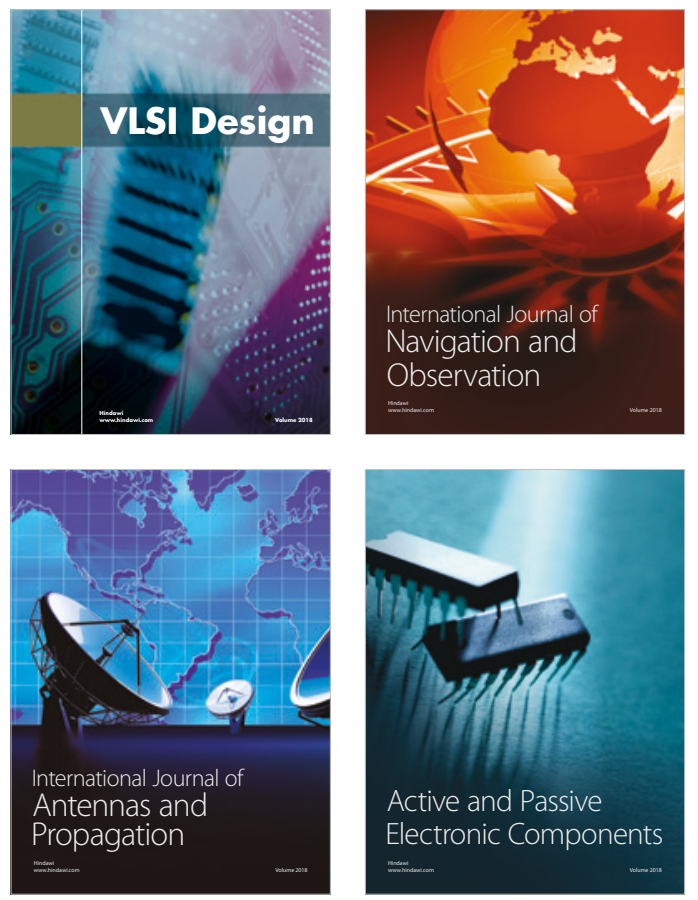
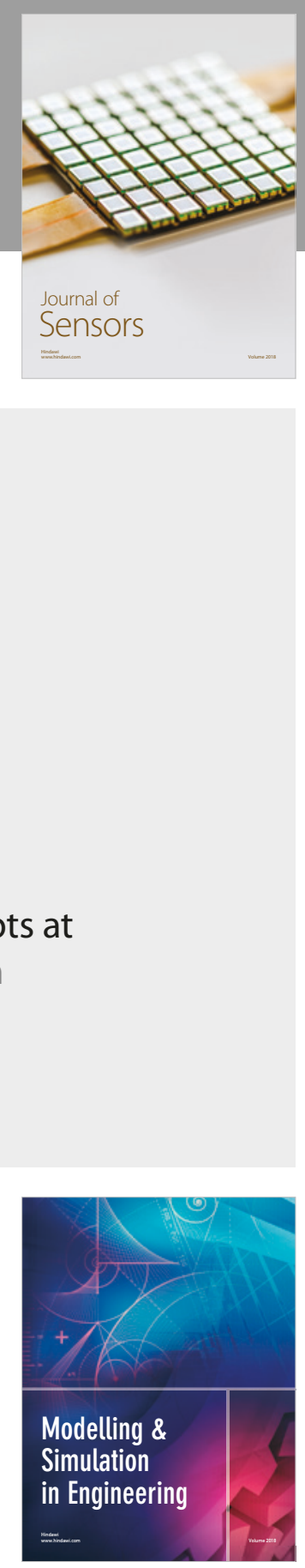

\section{Advances \\ Multimedia}
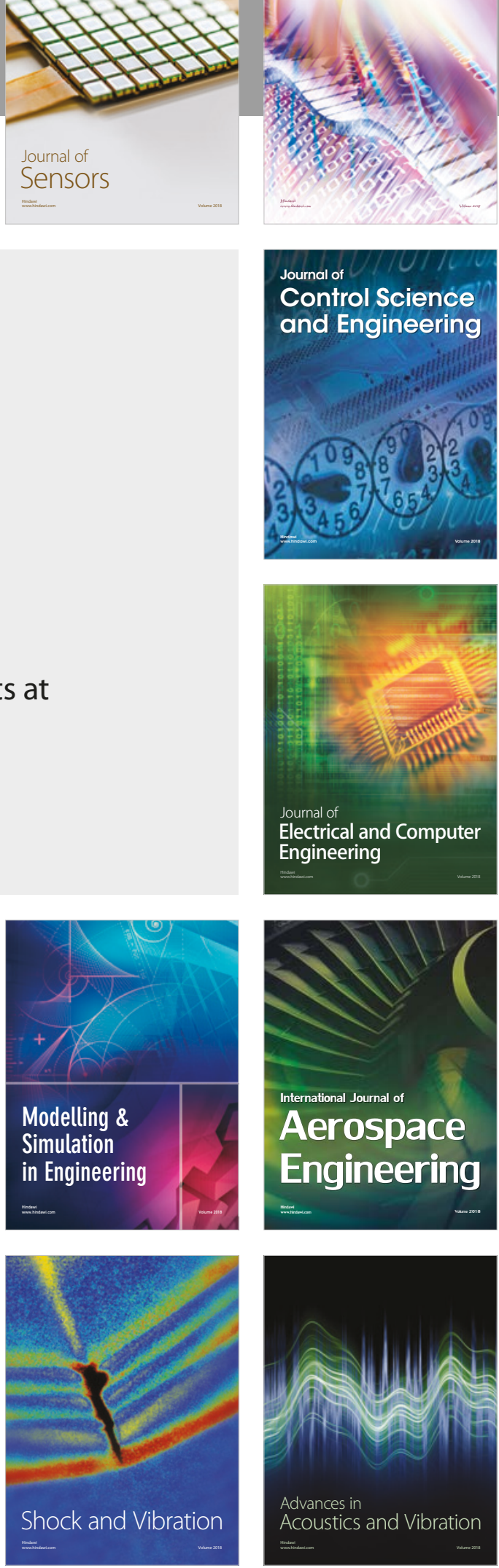